\title{
Antropometría histórica de Chile: evolución de la estatura de la población en el largo plazo, siglos XVIII-XX ${ }^{1}$
}

\section{Anthropometric history in Chile: height evolution of the population in the long-run, XVIII to XX centuries}

\author{
Manuel Llorca-Jaña ${ }^{2}$, Roberto Araya ${ }^{3}$, Juan Navarrete-Montalvo ${ }^{4}$
}

\begin{abstract}
Resumen
La estatura promedio de una población se ha considerado recientemente como un buen indicador de bienestar biológico, y por tanto de niveles de vida y desarrollo económico. Este artículo entrega la primera serie disponible para Chile, aportando la evolución de la estatura promedio de soldados chilenos (varones) nacidos desde la década de 1730 hasta la de 1980, usando una muestra de 6.200 individuos. Dicha muestra puede tomarse como un buen proxy de la estatura promedio de la población chilena (masculina) para el período bajo estudio. Del análisis de los datos, nuestras principales conclusiones son: i) a mediados del siglo XVIII la estatura promedio de los chilenos era relativamente alta si se compara con Chile mismo en otros períodos, así como con otros países de la región y de Europa; ii) en el siglo XIX la estatura promedio de los chilenos cae durante un período prolongado; iii) en el siglo XX se observa un importante aumento de la estatura promedio masculina, aunque en el mundo desarrollado la estatura creció mucho más rápido que en Chile.
\end{abstract}

Palabras claves: niveles de vida biológicos, estatura física, altura, Chile, historia antropométrica.

\begin{abstract}
The average height of a population has been recently taken as a good indicator of biological welfare, and therefore of standards of living and economic development. This article provides the first available series for Chile, providing the evolution of the average height of Chilean soldiers (male) born from the 1730s to the 1980s, using a sample of 6.200 individuals. This sample can be safely taken as a good proxy of the average height of Chilean male population for the period under study. Having analysed our data, our main conclusions are: (i) around mid-eighteenth century the average height of Chileans was rather high if compared to Chile itself, as well as to other countries of the region and Europe; (ii) during the nineteenth century the average height of Chileans declined during a long spell, (iii) in the twentieth century there was an important increase in the average male height, but in the developed world height increased faster than in Chile.
\end{abstract}

Keywords: biological standard of living, physical stature, height, Chile, anthropometric history.

Recibido: 17 mayo 2017. Aceptado: 8 septiembre 2017

1 Este artículo recibió financiamiento de Proyectos Basales y del FONDECYT Regular 1180005.

2 Profesor titular, Departamento de Economía, Universidad de Santiago de Chile, CHILE. Email: manuel.llorca@usach.cl.

3 Investigador asociado, Centro Internacional de Historia Económica, Empresarial y de la Administración Pública, Facultad de Administración y Economía, Universidad de Santiago de Chile, CHILE. Email: roberto.arayav@usach.cl

4 Investigador asociado, Centro Internacional de Historia Económica, Empresarial y de la Administración Pública, Facultad de Administración y Economía, Universidad de Santiago de Chile, CHILE. Email: juan.navarrete@usach.cl 


\section{Introducción}

Una de las grandes preocupaciones de la historiografía económica es explicar la evolución de los niveles de vida de la población en el largo plazo. Normalmente los mismos se miden a través de indicadores como PIB per cápita, esperanza de vida, niveles de escolaridad, tasa de mortalidad y natalidad, teléfonos por habitante, camas hospitalarias por mil habitantes, médicos por mil habitantes, consumo de energía per cápita, proporción de población rural versus urbana, gasto en educación e investigación y desarrollo, entre muchos otros. Sin embargo, aquellos investigadores interesados en estudiar niveles de vida de América Latina desde antes de la primera globalización (ca. 1870-1914) se ven enfrentados a una difícil situación: la falta de datos para casi todas estas variables. En palabras de Dobado y García Montero (2014), nos vemos enfrentados a una auténtica "caja negra": mientras más atrás nos movemos en el tiempo, menor es la riqueza de la evidencia cuantitativa disponible (Dobado, 2015). Es por ello que la historiografía económica recurre a indicadores alternativos, para indagar en la evolución de los niveles de vida de nuestros pueblos.

Probablemente el más popular de estos indicadores alternativos de desarrollo económico sean los salarios reales, sobre todo después de la publicación de los trabajos fundacionales de Robert Allen y otros colegas europeos (Allen, 2001; Allen et al., 2011; Allen y Weisdorf, 2011; Allen et al., 2012). Ante la recurrente ausencia de PIB per cápita para largos períodos, el salario real se considera un buen proxy de ingreso medio de la población, sobre todo de trabajadores no calificados, pues los mismos representarían los ingresos promedios de un buen porcentaje de la población bajo estudio. Más importante para este artículo, otro indicador de desarrollo y niveles de vida que ha ganado creciente popularidad es la estatura de la población (Steckel, 1995), ${ }^{5}$ un indicador de salud, netamente antropométrico, normalmente alejado del análisis económico.

5 A partir de 1980, la estatura poblacional comenzó incluso a ser recopilada por el Banco Mundial en sus reportes de niveles de vida por países (Steckel, 1995).
Sin embargo, esta lejanía es solo aparente; es bien sabido que mientras más alta es la población bajo estudio, se asume que mejor es su nivel de vida, ceteris paribus, toda vez que nutrición, educación, salud, condiciones laborales y estatura están estrechamente ligados (Komlos, 1998; Steckel, 1995; Blum, 2016; Costa et al., 2004), al igual que los genes (Lettre, 2009; Vercellotti et al., 2014). La estatura de una persona está en buena medida determinada por el acceso a nutrientes (proteínas en particular) a lo largo de su vida temprana, así como por el medio ambiente en que vive y sus genes (Kelly and Komlos, 2016; López-Alonso, 2016; Steckel, 1995). ${ }^{6}$ Sabemos mucho de la historia macroeconómica de Chile (Díaz et al., 2016), pero poco respecto de cómo estas tendencias macro han impactado los niveles de vida biológicos y materiales de la población. Asimismo, como en el caso mexicano (López Alonso, 2015), no existe en Chile ningún intento por medir los niveles de vida de la población en un período tan largo como el cubierto en este artículo.

De este modo, el presente estudio tiene por objeto principal elaborar la primera serie de estatura de la población adulta (masculina) chilena en el largo plazo, en concreto desde ca. 1730 hasta 1989 (excluidas las décadas de 1810-1820, por falta de datos), usando registros militares de soldados varones. Dicha metodología, esto es, aproximar la estatura de soldados del ejército a la estatura total del país en que nacieron ha sido aceptada como un buen proxy, toda vez que los soldados de los ejércitos regulares normalmente pertenecen a estratos socioeconómicos bajos, representando así al grueso de la población bajo análisis (Steckel, 1995).

Dicha serie sobre la biología humana de Chile es el primer intento por medir niveles de vida en Chile para un período tan extenso, siendo una importante contribución a estudios de desarrollo económico

6 Respecto de los genes, se ha demostrado que éstos son determinantes de la estatura de una persona, pero a nivel individual (Lettre, 2009; Vercellotti et al., 2014; López-Alonso, 2007). Por el contrario, a nivel agregado las diferencias genéticas se vuelven menos importantes: diferencias genéticas se cancelan al comparar promedios entre la mayoría de las poblaciones de distintas localidades, siendo los factores medioambientales más relevantes (Steckel, 1995; López-Alonso, 2007). 
de nuestro país, complementando información ya disponible sobre otros indicadores para algunos subperíodos. Bien es sabido que cuando analizamos niveles de vida no podemos concentrarnos en un solo indicador (p.e., PIB per cápita o salarios reales); lo recomendable es siempre tener tantos indicadores a la mano como sea factible. Relacionado con esto, muchas veces la evolución de indicadores de bienestar biológico no sigue la misma trayectoria que los indicadores habituales de desarrollo económico, como PIB per cápita, lo que genera desafíos en la formulación de políticas públicas (López-Alonso, 2016).

Asimismo, la estatura no es solo un complemento a los indicadores convencionales, sino que en muchos aspectos es un indicador superior de prosperidad, debido a las limitantes propias del PIB, por poner un ejemplo (Steckel, 1995). En efecto, la estatura es una "medida directa" de bienestar, no indirecta como el PIB per cápita. La estatura media de la población es una medida que viene directamente del cuerpo humano, reflejando el uso que ha hecho él mismo de los nutrientes consumidos para poder trabajar o estudiar, combatir enfermedades y crecer (Salvatore et al., 2010), estando directamente correlacionada con mejor salud y mayor esperanza de vida (Steckel, 1995 y 2009; Komlos, 1985). Otra ventaja de este indicador es que permite distinguir entre "bienestar económico" y "bienestar biológico". El primero es una medida de poder de compra, mientras que el segundo refleja mejoras en condiciones de salud y nutrición (que pueden, o no, estar relacionadas a crecimiento económico). Finalmente, cabe destacar que cada vez más, historiadores económicos han comenzado a usar medidas antropométricas como un proxy de desigualdad, por ejemplo, al comparar estaturas de población de estratos socioeconómicos altos con estratos de ingresos bajos, por ocupaciones, o de mujeres versus hombres (López-Alonso, 2016; Steckel, 1995).

En concreto, en este estudio encontramos que: i) a mediados del siglo XVIII la estatura promedio de los chilenos era relativamente alta si se compara con Chile mismo en otros períodos, así como con otros países de la región y de Europa, sugiriendo, comparativamente, altos niveles de vida biológicos; ii) en el siglo XIX la estatura promedio de los chilenos cae durante un período prolongado, y por ende el bienestar biológico, tal como aconteció en otros países latinoamericanos; iii) en el siglo XX se observa un importante aumento de la estatura promedio masculina, sugiriendo un repunte en el nivel de vida de la población, pero en el mundo desarrollado (y parte de aquel en desarrollo) la estatura creció mucho más rápido que en Chile.

Estos resultados contradicen en buena parte los principales recuentos de la historia económica chilena tradicional y las tendencias de crecimiento económico de Chile en el largo plazo. Para el período colonial no existen estimaciones de desempeño económico, pero la historiografía tradicional ha sostenido que la economía colonial se caracterizaba por tener poco dinamismo, mientras que su población vivía casi al límite de la sobrevivencia, con un promedio de ingresos muy bajos (León, 2002a y 2002b; De Ramón, 1992; Villalobos, 1961; Pinto y Salazar, 1999). Nuestros datos sugieren otra historia, desafiando interpretaciones tradicionales: la población en la era colonial disfrutaba buenos niveles biológicos de vida. Para el siglo XIX, sus primeras décadas están poco documentadas cuantitativamente, pero el recientemente publicado trabajo de Díaz et al. (2016) da cuenta de un crecimiento sostenido, y prácticamente ininterrumpido desde fines de los años 1820 hasta la Primera Guerra Mundial. Nuestros datos de bienestar biológico dan cuenta de un fenómeno bien distinto: un deterioro importante de los niveles de vida en el siglo XIX, cuando el bienestar biológico no habría sido superior que en las últimas décadas coloniales. Finalmente, solo para el siglo XX hay algo de concordancia entre crecimiento económico y niveles de vida biológico: ambos mejoran substancialmente en los años 1930, 1940, 1950, 1960 y el segundo lustro de la década de 1980.

Antes de proseguir con la próxima sección es necesario señalar que, previo a este estudio, existen solo dos trabajos de antropometría histórica de Chile. Nos referimos al recientemente publicado estudio de Núñez y Pérez (2015) sobre estatura de niños chilenos (de edades entre 5 y 18 ańos) nacidos entre 1880 y 1997 . A pesar de lo pionero e innovador de dicho trabajo, el mismo cubre solo niños, en lugar de adultos, que es nuestro foco de estudio, $y$ además analiza un período mucho más acotado que el nuestro. El segundo estudio ligado al tema, pero 
menos cuantitativo, y para un período anterior, es el de Retamal (1993), pero lamentablemente en dicho estudio se empleó una muestra pequeña (300 individuos solamente), y la estatura fue registrada en categorías discretas tales como alta, media y baja, lo que no permite realizar comparaciones con nuestros datos (otros artículos que han aportado datos para períodos puntuales son Cárcamo y Almagia, 2000 y Erazo et al., 2005). Vale decir, antes de nuestro trabajo es muy poco lo que sabíamos sobre datos antropométricos para la población adulta chilena. $^{7}$

En lo que sigue, este artículo contiene otras cuatro secciones. En la segunda sección repasamos brevemente la historia antropométrica de América Latina, para poder posicionar el caso chileno en un contexto más amplio, y brindar al lector una revisión resumida de lo ya publicado para la región. La siguiente sección trata sobre las fuentes empleadas en nuestro estudio, la metodología y los problemas que hemos enfrentado. Posteriormente pasamos a los resultados, primero para el período colonial, seguido del siglo XIX, y terminando con el siglo XX, discutiendo los mismos. Finalmente, y antes de las conclusiones, hemos incluido un análisis comparativo de nuestros resultados con la estatura de la población en otras regiones del mundo, con especial acento en el caso latinoamericano.

\section{Historia antropométrica mundial, en América española y América Latina: un recuento}

El uso sistemático de estatura adulta como un indicador de desarrollo económico es relativamente nuevo en estudios históricos, descansando fuertemente en estudios previos de antropología física. Dicha rama de la antropología ha demostrado que la estatura adulta está fuertemente relacionada con el estatus "nutricional neto" en los primeros años de vida del ser humano, sobre todo antes de los tres años de vida. Los iniciadores de esta área del conocimiento fueron Le Roy Ladurie, Jean Paul Aron y Nicole Bernageau, quienes publicaron sus estudios

7 Incluso para las últimas décadas (Cárcamo y Almagia, 2000). pioneros a fines de los años sesenta para Francia (Ladurie et al., 1969; Salvatore et al., 2010).

Posteriormente, la historia económica hizo suya dichas técnicas, sobre todo a partir de los años 1970 y 1980, cuando historiadores económicos sistematizaron el uso de datos de estatura de adultos para los últimos 200 ańos. Cabe destacar en particular los trabajos de Fogel (1993 y 2004), Fogel et al. (1983), Margo (Margo y Steckel, 1982), Steckel (1997, 1995), Eltis (1982), y luego Komlos (1989, 1994; Komlos y Baten, 1998), Floud (Floud et al., 1990), los cuales dieron nacimiento a lo que hoy se conoce como "historia antropométrica". El principal propósito de estos estudios fue determinar cómo cambió la estatura promedio de la población en el largo plazo (Komlos, 2004). Con todo, los aportes al estudio del desarrollo económico han sido sustanciales, destacando la constatación que la estatura física de los países desarrollados declinó cuando los mismos comenzaron a industrializarse, exponiendo así algunos "costos ocultos" de la industrialización y la urbanización asociada a ella (Komlos, 2004, Steckel, 1995). El caso de los Estados Unidos sigue siendo intrigante. A partir del segundo cuarto del siglo XIX se observó una caída en la estatura, justo en un período en que medidas convencionales de desarrollo económico lo describen como próspero para la economía norteamericana (Steckel, 1995).

Las principales fuentes de información que han usado a la fecha los especialistas en esta área son registros militares, registros de cárceles, registros de esclavos, de hospitales públicos, pasaportes y cédulas de identidad. Vale decir, normalmente fuentes oficiales (ligadas al Estado), y que habitualmente cubren las clases bajas, que en sociedades preindustriales constituyen la mayoría de la población (Salvatore, 1998), lo que agrega aún más valor a este tipo de metodologías. Menos común (por falta de fuentes) es el uso de esqueletos humanos, sobre todo para períodos anteriores a ca. 1700 , lo que se justifica cuando no se dispone de registros oficiales alternativos, aunque cabe destacar que dichos estudios son bastante limitados por lo escaso de la evidencia física en esqueletos propiamente tal. ${ }^{8}$ Para un ejemplo para América

8 En estudios con esqueletos se toma el largo del fémur para estimar la estatura del individuo (Costa et al., 2004). 
Latina, Bogin y Keep (1998) encontraron que después de la conquista española hubo una caída en la estatura de la población de América Central y Sudamérica, que se prolongó hasta ca. 1939 (para otros estudios, ver Márquez y Del Angel, 1997; Márquez et al., 2002; Steckel, 2005).

Más allá de estos estudios para países desarrollados, desde los años 1990 comenzamos a contar con valiosos estudios para un puñado de países latinoamericanos. ${ }^{9}$ El primer período cubierto es la era precolombina, en particular la población mayas (Márquez y Del Angel, 1997; Márquez et al., 2002; McCaa et al., 2002). Uno de los resultados más importantes que han encontrado estos colegas es una caída secular en la estatura de los mayas (López-Alonso, 2016). Para el caso chileno, Costa et al. (2004) encontraron que la estatura de los hombres aumentó en San Pedro de Atacama durante el período de influencia Tiwanaku (400-900 DC). Sin embargo, justo es reconocer que éste es por lejos el período que menos atención ha recibido en la literatura, debido principalmente a la escasez de evidencia antropológica.

Con posterioridad al arribo español a las Américas, los principales países para los que existen trabajos son Argentina, México, Colombia y Brasil. El caso argentino ha sido trabajado en particular por Salvatore $(1998,2004,2007,2009)$. En un trabajo pionero Salvatore estimó la altura media de la población para el período ca. 1780-1840, distinguiendo dos tendencias claras: una caída en la estatura de los conscriptos a fines de la Colonia, y luego un aumento posterior a la Independencia. Más tarde, Salvatore cubrió el período 1900-1934, constatando que durante 1900-1913 hubo un deterioro importante en "nutrición neta", pero que entre 1918 y 1939 se observó una mejoría en la salud y nutrición de soldados argentinos. En un estudio postrero, Salvatore cubrió el período 1850-1950, no solo usando datos de conscriptos, sino además de prisioneros, concluyendo que durante la era del progreso liberal (ca. 1880-1913) hubo menos avances en el bienestar

9 El primer estudio antropométrico para América Latina fue el de Ordóńez y Polania, 1992, para Colombia. Para una revisión de los trabajos publicados sobre América Latina, ver López-Alonso, 2016; y Baten y Carson, 2010 . nutricional de lo que podría haberse esperado sobre la base de indicadores alternativos como PIB per cápita. Por el contrario, durante el período conocido como la "gran demora" argentina (ca. 1913-1939), para sorpresa de muchos, hubo notables aumentos de bienestar biológico. El último de los estudios de Salvatore cubre un período posterior, ca. 19151950, para el cual se encontró un sostenido aumento en la estatura antes de $1940 \mathrm{y}$ un posterior decremento de la misma (Salvatore, 2009). Con todo, el caso argentino está bien cubierto para 1770-1950.

El caso mexicano ha sido también muy bien estudiado (Grajales-Porras y López-Alonso, 2011; López-Alonso y Porras-Condey, 2003; López-Alonso, 2015 y 2007; Scott Carson, 2005; y Amílcar Challú, 2009 y 2010). En orden cronológico, Challú advirtió una caída en la estatura de la población mexicana para fines de la era colonial y principios de la Independencia, constatando además que la estatura de la población rural habría caído más que la urbana, un resultado a todas luces sorprendente (i.e. conocido es el impacto negativo que causó la urbanización en las condiciones de vida de la población en el mundo desarrollado). También para el siglo XVIII, Grajales-Porras y López Alonso (2011) encontraron que, para 1791-1792, los mexicanos eran considerablemente más bajos que los europeos y los norteamericanos. Siguiendo con Carson, quien usó registros de prisioneros mexicanos en cárceles norteamericanas de Texas, dicho autor encontró que la estatura de estos prisioneros se estancó hacia fines del siglo XIX, y que además los prisioneros de origen mexicano eran unos dos centímetros más bajos que los norteamericanos. López-Alonso y Porras (2003), por su parte, cubrieron el período 18701950, haciendo uso de registros de prisioneros y datos de pasaportes, y descubrieron que, a pesar del rápido crecimiento económico experimentado por México durante dicho período, en la mayor parte de la población mexicana hubo tan solo un modesto aumento en su estatura. Sin embargo, la estatura de las élites sí que aumentó de forma considerable. En la misma línea, López Alonso, esta vez haciendo uso de registros de la milicia (clases bajas), y nuevamente de pasaportes (clases altas), confirma que durante el Porfiriato (1876-1910) la clase trabajadora no aumentó su estatura, pero sí lo hizo al final del gobierno de Cárdenas. En contraste, la estatura de las élites 
aumentó durante todo este período, graficando con ello la (creciente) desigualdad de la sociedad mexicana. Para el período posterior a 1950, un estudio reciente muestra que aun cuando la estatura de la población mexicana mejoró, la desigualdad entre clases y regiones persiste (López-Alonso y Grajales, 2015).

Respecto de Colombia, Meisel y Vega (2007) condujeron un estudio pletórico, partiendo en la primera globalización, y haciendo uso de la mayor base de datos jamás utilizada para analizar la estatura de la población de cualquier país latinoamericano. Estos autores trabajaron con más de 9 millones de registros, proporcionados por el Registro Civil colombiano (cédulas de identidad y pasaportes). Sus principales resultados son que: hubo un aumento de la estatura de la población de $9 \mathrm{~cm}$ entre 1905 y 1985; la élite colombiana era mucho más alta que el resto de la población; los hombres colombianos eran también bastante más altos que las mujeres; y hubo un importante proceso de convergencia en estatura a nivel de regiones e intrapersonal. Posteriormente, Meisel y Acosta (2013) publicaron otro estudio sobre diferencias en estatura según etnicidad, para 1965-1990, en el que comprobaron que los afrocolombianos eran el grupo étnico más alto del país, mientras que los indígenas, el más bajo; pero que la brecha entre los indígenas y el resto de la población se redujo durante ese período.

Para Brasil, el principal trabajo disponible descansa en registros de prisioneros. Frank (2006) constató que los esclavos nacidos en Brasil experimentaron una caída en su estatura entre los años 1860 y 1880, y que además la población rural habría sido más baja que la urbana. Por su parte, Baten y otros (2009) advirtieron que entre ca. 1810 y los años 1860 la población urbana no creció mucho, lo que contrasta con el período 1860-1880, durante el cual se evidenció un gran crecimiento de la población citadina. Por su parte, Monasterio (2013) analizó la estatura de la población en Rio Grande entre 1880 y 1914, constatando que los hijos de inmigrantes eran bastante altos a nivel mundial, y que no había mayor diferencia entre la estatura de los inmigrantes y sus hijos. Para un período posterior, de Oliveira y Quintana-Domeque (2014) descubrieron diferencias importantes en la estatura entre los más ricos y los más pobres para 1950-1980. Resumiendo, el caso brasileño está bien cubierto solo desde inicios del siglo XIX.

El mismo estudio de Baten y otros, citado en el párrafo anterior, pero para Perú, determinó que entre ca. 1820 y la década de 1880 el crecimiento de la población fue moderado. En ambos casos se encontró una diferencia substancial en la estatura promedio entre clases sociales. También para Perú, tenemos el estudio de Twrdek y Manzel (2010), quienes usando registros penitenciarios para ca. 1820-1880 concluyeron que la estatura de la población peruana se estancó en todo este período, a pesar del crecimiento económico del país durante el boom exportador liderado por el guano. Otro estudio ligado a estatura de latinoamericanos, aunque menos relevante para este artículo, es Godoy, 2006.

\section{Fuentes, metodología y desafíos metodológicos: el caso chileno}

Como ya se mencionó, a pesar de la existencia de diversos e importantes estudios sobre estatura de la población para varios países de América Latina, es poco lo que se sabía para Chile. En este estudio cubrimos el período ca. 1730-1980, y dada la novedad del mismo, es importante detenerse en las fuentes utilizadas, así como en la metodología empleada para validar nuestros datos. Para ello vamos a dividir el período en tres ciclos: el colonial, siglo XIX y el siglo XX. Antes de proseguir, cabe destacar que en la mayoría de los estudios de estatura disponibles para América Latina (y el mundo), la principal fuente de información la constituyen registros militares nacionales. Nuestro caso no es la excepción: hemos hecho uso de esta misma fuente.

Para el primero de estos lapsos (aquellos nacidos ca. 1730-1809), nuestros datos provienen de las hojas de servicio del Real Ejército, que se encuentran disponibles en el Archivo Histórico Nacional de Chile, Fondo Contaduría Mayor, Series I y II (ANCHCM de aquí en adelante). Las hojas de servicio incluyen, normalmente, la siguiente información: nombre, año de ingreso, estatura (en pies, pulgadas y líneas),${ }^{10}$ color de piel, color de pelo, localidad

10 Un pie era equivalente a 12 pulgadas y una pulgada a 12 líneas. 
ingreso, localidad procedencia, y ocasionalmente el grado militar (pocos casos). En total, nuestra muestra depurada para este período (eliminando soldados de edades no comprendidas en el estudio y soldados nacidos fuera de Chile) consta de 1.786 casos, en promedio 223 por década. ${ }^{11}$ Llegado este punto, resulta conveniente reiterar que hemos agrupado nuestros datos según cohortes de nacimiento por década, tal como es habitual en estudios del área. Vale decir, calculamos la estatura promedio para los nacidos en la década de 1730, luego de 1740, y así sucesivamente, hasta la década de 1980.

Para el segundo y tercer períodos en conjunto, nacidos ca. 1830-1989, hemos recurrido a diversos fondos documentales disponibles en el Archivo Histórico del Ejército (AHE de aquí en adelante), que almacenan las hojas de filiaciones, contratos y fichas médicas de miembros del ejército regular, en particular del cuadro permanente del Ejército, pero también de veteranos del mismo. ${ }^{12}$ En total, nuestra muestra depurada para este período (eliminando soldados de edades no comprendidas en el estudio y soldados nacidos fuera de Chile) consta de alrededor de 4.400 casos, con un promedio de 259 casos por década. Los mismos fueron obtenidos de 448 volúmenes distribuidos en 10 fondos documentales distintos. Como podrá apreciarse, el promedio de filiaciones encontradas por volumen (alrededor de 10) es bastante bajo: la pesquisa de información fue un proceso lento, dada la dispersión de la fuente.

Un aspecto importante de los registros militares en el largo plazo es determinar si el reclutamiento era voluntario o por conscripción. En el caso chileno, para el período colonial existieron tres tipos de cuerpos: milicias urbanas, milicias disciplinadas y ejército profesional (según ordenanzas de Carlos III), siendo el reclutamiento voluntario en todos los cuerpos. Los reclutas que se incorporaban al cuerpo profesional eran motivados por la estabilidad que generaba

11 Fueron excluidos 138 casos por diversas razones, principalmente por no estar dentro del rango de edad (17-55 años) que nos hemos fijado (ver abajo para más detalles), o por tratarse de personas nacidas fuera de Chile).

12 Por razones de confidencialidad, para el siglo XX no se ingresó el nombre de los soldados, cumpliendo así con todos los protocolos establecidos por la institución castrense para uso de información con fines académicos. un salario fijo, así como por la posibilidad de ascenso social. En cuanto a las milicias, la mecánica de su reclutamiento imponía que los vecinos de las ciudades se agruparan y recibieran entrenamiento militar para la defensa de sus comunidades, principalmente en caso de guerra con potencias europeas. De estos tres cuerpos, el más numeroso eran las milicias, que representaban un $90 \%$ del total, al menos en 1792 (Hernández, 1984; Ossa, 2016; Allende, 1963). Durante las guerras de la Independencia, los diversos gobiernos utilizaron el sistema de leva forzosa. A partir de la década de 1830 el ejército profesional mantiene las características de su antecesor colonial en cuanto a funciones y enrolamiento (prueba de ello es que la primera ordenanza militar republicana de 1839 reproduce en buena parte el texto borbónico de Carlos III). Por su parte, las milicias cívicas cambian su cariz meramente defensivo-castrense para ampliarlo a uno de control del orden público y transmisor de los ideales de civilidad republicana. A partir de 1848 las unidades cívicas obtienen su reglamento propio, donde queda establecido su rol como "reserva" del ejército profesional. En 1896 se realiza el primer ensayo de servicio militar obligatorio, que reorganizaba la Guardia Nacional, ${ }^{13} \mathrm{y}$ cuatro años más tarde se instituye definitivamente el servicio militar obligatorio en Chile (Delgado, 2015; Hernández, 1984).

Respecto de los mayores desafíos metodológicos de la antropometría, uno de los problemas que ha enfrentado la historia antropométrica que ha hecho uso de registros militares es que las muestras que se utilizan podrían estar truncadas debido a la estatura mínima requerida por los ejércitos (sobre este tema, ver Wachter, 1981; Komlos y Kim, 1990). Esto es, las muestras podrían no distribuirse de forma normal, ${ }^{14}$ sino "cargadas" a la izquierda, no siendo (por tanto) del todo representativas de la población bajo estudio, toda vez que una parte de la distribución de la estatura subyacente no está incluida en la muestra (Salvatore y Baten, 1998; Komlos, 2004).

13 Ese año se promulgó el proyecto de ley que reorganizó la Guardia Nacional, estableciendo que todo ciudadano de entre 20 y 40 años de edad debía, obligatoriamente, presentarse a ésta (Delgado, 2015).

14 Lo óptimo, en estudios de antropometría histórica, es siempre que la estatura de la población este normalmente distribuida. Komlos y Kin, 1990; Komlos, 2002. 
Asociado a esto, otro problema que podría presentarse es el denominado heaping vinculado a la estatura mínima, pero también a cifras "redondas" (p.e., 5 pies y 2 pulgadas, o $160 \mathrm{~cm}, \mathrm{o} 165 \mathrm{~cm})$. Vale decir, se ha observado un inusual número de conscriptos con, exactamente, la estatura mínima requerida, la que probablemente se reportaba (falsamente) como tal para conscriptos de menor estatura, en períodos de gran demanda de militares, evitando así dejarlos fuera de las milicias o ejércitos. En otras palabras, cuando la demanda por conscriptos fue mayor que la oferta, pudo haberse relajado el requerimiento de estatura mínima. Por tanto, los conscriptos agrupados con esta estatura mínima incluyen a los que la cumplían, pero también a aquellos que estaban por debajo de este requerimiento, inflando así la estatura promedio de la muestra. Asimismo, para el período colonial, el personal encargado de realizar las mediciones de estatura redondeaba a pies y pulgadas, obviando las líneas.

Respecto del primer problema -el establecimiento de estaturas mínimas para el ejército colonial chileno-, Julio Retamal (1993) constató que se estableció una estatura mínima de 5 pies $(162,4 \mathrm{~cm})$, tal como acontecía en Buenos Aires. Asimismo, Dobado y García (2014) también encontraron que para Nueva España y la Capitanía General de Venezuela la estatura mínima era igualmente de 5 pies. Sin embargo, debemos mencionar que este límite no era uniforme en todas las colonias españolas. Por ejemplo, en La Habana del siglo XVIII se imponía una estatura mínima levemente superior, de 5 pies y una pulgada, y en Yucatán, aún más alta: de 5 pies y 2 pulgadas, probablemente porque en ambas localidades había mayor oferta de soldados.

En los inicios del período republicano, el ejército chileno continuó rigiéndose implícitamente por las ordenanzas espańolas. El 25 de abril de 1839 se promulgó una primera ordenanza, y en su primer artículo se estipulaba que la estatura mínima seguía siendo 5 pies. La ordenanza de 1839, con correcciones, rigió hasta 1869 , pero la de 1869 mantuvo también la estatura mínima en 5 pies. Posteriormente, en 1896, la estatura requerida fue relajada, bajando a $160 \mathrm{~cm}$. No hemos podido encontrar información sistemática para el siglo XX, pero sabemos que en 1931 la estatura mínima necesaria era aún menor, apenas $155 \mathrm{~cm}$, pero que en 1956 y 1965 había subido a $165 \mathrm{~cm}$, y en 1974 nuevamente bajado a $160 \mathrm{~cm}$.

Otro problema metodológico que encuentran los historiadores antropométricos es determinar hasta qué edad crecía la población bajo análisis, para así, al analizar estaturas de adultos, considerar solo a aquellos soldados por sobre esta edad, desechando a los que aún estaban en crecimiento. Hoy se cree que las personas crecen hasta los 17-18 años en los países desarrollados, pero para inicios del siglo XIX, por ejemplo, este límite se suponía más cercano a los 20 años (Salvatore y Baten, 1998). Adicionalmente, también es sabido que las personas decrecen en estatura a partir de cierta edad, por lo que lo recomendable es también excluir a adultos a partir de cierta edad (alrededor de los 55 ańos). Al respecto, cabe destacar que, de los trabajos disponibles para América Latina, diversos autores han optado por los siguientes rangos etarios: 16-39 (Grajales-Porras y López-Alonso, 2011); 17-52 (Baten et al., 2009); 20-50 (Frank, 2006), 22-49 (Salvatore, 1998); 2355 (Carson, 2005). Como límite inferior de edad adulta, Meisel y Vega (2007) tomaron los 18 años; Salvatore (2007), los 21 años en otro trabajo, mientras que Grajales-Porras y López-Alonso (2011) lo estimaron en 23 años. Como vemos, no hay un rango uniforme en la literatura especializada, quizás porque en su margen no se observan mayores diferencias de estatura. Es por ello que, como ya han hecho otros autores prominentes en esta área, en este estudio hemos considerado a los soldados con edades entre los 17 y los 55 años, para incluir así el mayor número posible de casos en el estudio, reconociendo que existe cierta controversia al respecto.

Dada dicha polémica, realizamos un análisis de la estatura por edades, prestando especial atención al rango 17-22 ańos. Nuestros datos revelan que la estatura promedio para nuestra muestra para las edades $17-22$ es de $167,8 \mathrm{~cm}$, mientras que para el rango 23-55 es de 167,6; es decir, muy similar al anterior. Esto sugiere que el rango que definimos como 17-55 no presentaría mayores problemas relativos a una supuesta población que seguiría en crecimiento. Volveremos sobre este punto en la sección Resultados. Por su parte, cabe destacar que, tal como lo han hecho otros autores, hemos asumido que los soldados eran medidos descalzos (Grajales-Porras 
y López-Alonso, 2011). Para el período colonial, la ordenanza arriba citada deja claramente establecido que, para los conscriptos, su estatura debía ser la "que pase de cinco pies, medido descalzo". Asimismo, en el primer instructivo que tenemos disponible para el Ejército de Chile después de la Independencia, queda claramente establecido que los soldados eran medidos descalzos.

Finalmente, otro problema significativo en términos metodológicos, pero que afecta solo al período colonial y primeras décadas post Independencia, guarda relación con la conversión de pies y pulgadas a centímetros que debemos realizar si queremos analizar series de largo plazo (empalmando el período colonial con el republicano), así como establecer comparaciones entre países. Ricardo Salvatore, en sus primeros estudios para Argentina colonial, usó la tasa 1 pie $=30,5 \mathrm{~cm}(2,542 \mathrm{~cm}$ por pulgada, o pie inglés $)$, mientras que Dobado y García (2014) adoptaron el pie de París o Pie de Rey (1 pie $=32,48 \mathrm{~cm}$, o 2,707 $\mathrm{cm}$ por pulgada). Como podrá apreciar el lector, no estamos hablando de diferencias menores (el pie de París es un 6,4\% más largo que el pie inglés). Por si esto fuera poco, en Chile el sistema métrico decimal fue adoptado de forma oficial en 1848, con la publicación de la Ley de pesos y medidas. En dicho cuerpo legal se expresa que para los antiguos pesos y medidas (no se señala desde cuánto antes), un pie era igual a $27,86 \mathrm{~cm}$ (2,322 por pulgada), denominado pie castellano o de Burgos (Cámara Hueso, 2006), ${ }^{15}$ vale decir, bastante menos que la medida inglesa o el pie de París. Sin embargo, esto no aplicaba necesariamente al estamento castrense. En virtud de estas importantes diferencias, en un artículo contundente, Cámara (y luego Challú) dejó la discusión zanjada: lo correcto es usar el pie de París para todas las conversiones en Espańa y sus colonias. ${ }^{16}$ En efecto, admitiendo su error, el mismo Salvatore corrigió este problema en un trabajo posterior para Argentina. ${ }^{17}$ Para aclarar, los datos presentados en este estudio hacen uso del pie de París.

15 La misma conversión se hizo en España en 1858.

16 El pie de París se usaba tanto en España como en México (Challú, 2009 y Cámara Hueso, 2006).

17 Baten mismo, coautor de Salvatore (1998), reconoció abiertamente el error de usar el pie inglés (Baten y Carson, 2010, p. 142).

\section{Resultados}

\section{Período colonial}

En términos descriptivos, la Tabla 1 incluye las características generales de la muestra que hemos agrupado para el período colonial. Lamentablemente no pudimos recopilar un número uniforme de casos para cada década, pero tenemos la certidumbre de que el período entre la década de 1730 y la de 1800 está bastante bien cubierto. En efecto, nuestros casi 1.800 casos constituyen un universo no muy distinto de los 2.564 casos que usaron Dobado y García Montero (2014) para varios países, y muy por encima de los 300 casos considerados por Salvatore y Baten (1998) para Buenos Aires, ambos trabajos para el período colonial. Vale decir, tenemos un buen tamaño muestral para este período.

En términos generales, el resultado más contundente de nuestro estudio para la era colonial es que la estatura promedio de los soldados con edades de entre 17 y 55 ańos fue de $167,3 \mathrm{~cm}$ para los nacidos entre las décadas de 1730 y de 1800 . Desagregando por décadas de nacimiento, podemos observar que los nacidos en las décadas de 1750 y 1760 presentan la estatura máxima de todo el período colonial, y que la estatura de los soldados chilenos habría declinado en las décadas de 1770, 1780, 1790 y 1800. En cualquier caso, la diferencia entre la década de mayor estatura y la de menor estatura es de $2,3 \mathrm{~cm}$, con cambios menores entre décadas, lo que habla de una relativa estabilidad de esta variable, así como de la calidad de los datos. En términos absolutos, esta estatura promedio es relativamente alta, comparado con estaturas promedios de Chile para períodos posteriores, así como con otras regiones, cosa que analizaremos más adelante. Respecto de Chile mismo, la estatura promedio que observamos para el período colonial se alcanzó o superó en las décadas de 1830 y 1840 (de forma intermitente) y se volvió a alcanzar de manera sostenida recién después de las primeras décadas del siglo XX.

Respecto de la calidad de los datos, señalamos al inicio que la estatura mínima impuesta en América española para los soldados era de 5 pies $(162,4 \mathrm{~cm})$, y que por tanto uno esperaría una gran cantidad de 
Tabla 1. Estatura de soldados nacidos en Chile en el período colonial, 1730-1809 (cm).

\begin{tabular}{|c|c|c|c|c|c|}
\hline $\begin{array}{c}\text { Década } \\
\text { nacimiento }\end{array}$ & Número de casos & $\begin{array}{c}\text { Estatura } \\
\text { promedio }\end{array}$ & Estatura mínima & Estatura máxima & $\begin{array}{c}\text { Desviación } \\
\text { estándar }\end{array}$ \\
\hline $\mathbf{1 7 3 0}$ & 12 & 167,3 & 162,4 & 176,6 & 4,6 \\
\hline $\mathbf{1 7 4 0}$ & 76 & 167,2 & 162,4 & 181,4 & 4,1 \\
\hline $\mathbf{1 7 5 0}$ & 171 & 167,8 & 151,6 & 186,8 & 4,8 \\
\hline $\mathbf{1 7 6 0}$ & 514 & 168,0 & 142,1 & 183,4 & 4,7 \\
\hline $\mathbf{1 7 7 0}$ & 611 & 167,2 & 143,5 & 189,9 & 4,9 \\
\hline $\mathbf{1 7 8 0}$ & 208 & 166,4 & 140,8 & 186,8 & 5,2 \\
\hline $\mathbf{1 7 9 0}$ & 149 & 166,0 & 146,2 & 192,2 & 4,8 \\
\hline $\mathbf{1 8 0 0}$ & 45 & 165,7 & 132,6 & 184,1 & $\mathbf{1 9 2 , 2}$ \\
\hline Total & $\mathbf{1 , 7 8 6}$ & $\mathbf{1 6 7 , 3}$ & $\mathbf{1 3 2 , 6}$ & $\mathbf{5 , 0}$ \\
\hline
\end{tabular}

Fuente: ANCH-CM.

estaturas reportadas en este nivel, cosa que efectivamente se manifiesta en nuestros datos (Figura 1). Vale decir, la muestra está sesgada hacia arriba, y truncada a la izquierda. En otras palabras, la estatura media reportada en la Tabla 1 es superior a la estatura media de la población a la que pertenecen esos soldados. ¿Cuán superior? La respuesta a tal pregunta es de difícil resolución, toda vez que desconocemos la estatura promedio de aquellos que no pudieron ingresar al ejército por medir menos de 5 pies, y qué proporción de la población representaban.

Asimismo, nuestra muestra también pone en evidencia que el mínimo de estatura reportado en las ordenanzas del ejército colonial fue estrictamen-

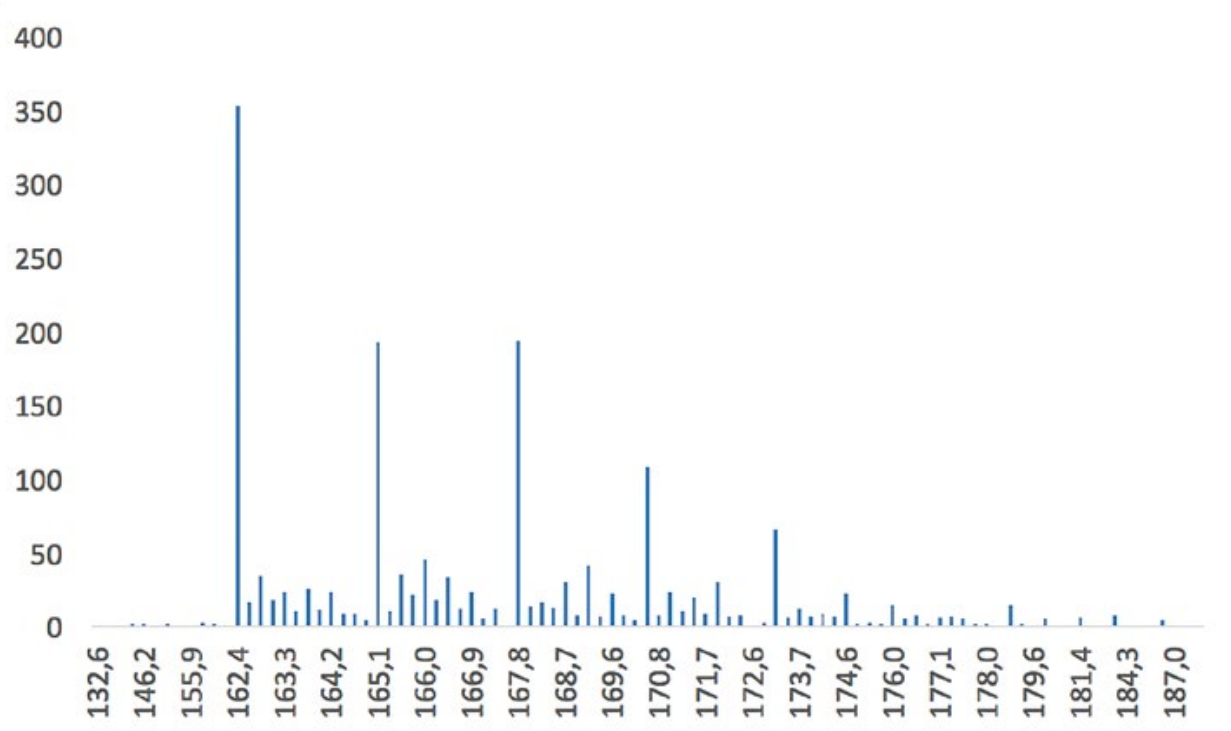

Figura 1. Frecuencia de las estaturas reportadas en nuestra muestra (cm): período colonial, 1730-1809. Fuente: ANCH-CM. 
te respetado solo en las décadas de 1730 y 1800 , exactamente el período para el cual tenemos la menor cantidad de datos, aunque justo es decir que para aquellas décadas donde no se adhirió a este mínimo, hay muy pocos datos por debajo de esta estatura mínima oficial. ${ }^{18} \mathrm{Y}$ en efecto, el valor que más se repite (moda) es $162,4 \mathrm{~cm}$ (5 pies), con un $20 \%$ de nuestros datos tomando este valor (Figura 1). Otro problema adicional que mencionamos en la sección metodológica, y que enfrentamos en nuestra muestra, es el denominado heaping (i.e. una alta e inusual concentración de datos en torno a valores específicos, “redondos"). En efecto, vemos en la Figura 1 una inusual cantidad de observaciones para las siguientes estaturas: 5 pies $(162,4 \mathrm{~cm}), 5$ pies y una pulgada $(165,1 \mathrm{~cm}), 5$ pies y dos pulgadas $(167,8 \mathrm{~cm}), 5$ pies $\mathrm{y}$ tres pulgadas, y 5 pies $\mathrm{y}$ cuatro pulgadas, cosa bastante común en muestras de soldados (Komlos, 2004). Vale decir, uno podría especular que los funcionarios a cargo de medir a los soldados no eran muy rigurosos con ingresar el número de líneas y redondeaban a la pulgada más cercana.

Evaluando el potencial impacto de estos dos problemas, dado que una línea son apenas $0.22 \mathrm{~cm}$, redondear hacia estaturas en solo pies y pulgadas no parece un problema tan grave, y que en promedio no afecta mayormente la calidad de nuestros datos (no al menos los promedios presentados en la Tabla 1). En efecto, si el redondeo es simétrico, cosa que la Figura 1 sugiere, entonces esta situación no representa un sesgo apreciable en el análisis, como ya lo dejaron establecido Komlos (2004) y Steckel (1995) para este tipo de muestras, toda vez que la estatura promedio no debería verse mayormente afectada.

Dicho lo anterior, la imposición de una estatura mínima sí podría representar un problema si estamos interesados en establecer de forma precisa la estatura

18 Incluso, legalmente, las ordenanzas coloniales permitían, en casos excepcionales, enrolar soldados por debajo de los 5 pies: "debiendo escoger siempre los soldados más experimentados, robustos, bizarros, bien formados, agiles y de acreditado honrado proceder; pero si esta última circunstancia no acompañase a la mejor talla [5 pies], deberá siempre preferirse con menos estatura el soldado de buenas costumbres, teniendo la competente y demás cualidades explicadas" [sic]. promedio de la población. Cuando el propósito de una investigación es esto último, que no es nuestro objetivo principal, los datos deben ser corregidos utilizando técnicas estadísticas que ya han sido aplicadas en estudios similares. Nos referimos en concreto al método propuesto por Komlos y Kim (1990), ratificado por Komlos (2004). Según estos autores, lo primero que debemos hacer es realizar una inspección visual de los datos disponibles para confirmar que la muestra está truncada, o si en su defecto se distribuye de forma normal. Si se confirma la truncación de los datos, los niveles de los mismos deben ser corregidos usando el método de Komlos y Kim.

En cualquier caso, la mayor contribución que hacen los estudios de antropometría histórica, y que pretendemos realizar nosotros en este trabajo, no es determinar el nivel absoluto de la estatura de la población bajo estudio, sino determinar las tendencias subyacentes a los datos analizados. Es decir, las variaciones entre décadas y las variaciones de tendencias en el largo plazo. Son estos cambios de tendencia los que nos entregan mayores antecedentes sobre modificaciones fundamentales en la economía, la demografía o el ambiente epidemiológico de una sociedad (Komlos y Kin, 1990). Adicionalmente, y por fortuna para nosotros, como ya demostraron Komlos y Kin (1990), cambios en la estatura media de una regresión truncada se mueven en la misma dirección de cambios de la "verdadera" media de la población (i.e. si no existiesen requerimientos de estatura mínima). A su vez, las comparaciones que realizamos en este artículo con otras regiones se efectuaron con los promedios truncados para cada país, o sea, son datos comparables. Concluyendo: los datos presentados en la Tabla 1 cumplen su propósito y son comparables a los disponibles para otros países.

\section{Siglo XIX}

Siguiendo las recomendaciones de Komlos (2004), cuando analizamos muestras para períodos muy prolongados, como el nuestro, lo recomendable es producir histogramas para varios subperíodos, en lugar de un solo histograma para toda la muestra. Es por ello que realizamos una inspección visual de los datos para el período ca. 1830-1899 (Figura 2), similar a la efectuada para el período colonial. 
Para sorpresa nuestra, el histograma da cuenta de una distribución relativamente normal, y donde ciertamente no operó mayormente la estatura mínima impuesta por el Ejército (aunque cierto es que hay una gran cantidad de datos en 5 pies), y el heaping que se observa (en torno a los 165 y los $170 \mathrm{~cm}$ ) es menos acentuado que en otras muestras.
Respecto de la estatura promedio para el siglo XIX $(166,7 \mathrm{~cm})$, la Tabla 2 da cuenta de una tendencia decreciente de la misma, e incluso una leve caída en relación al período colonial entre las décadas de 1850 y 1890 . En efecto, la estatura promedio en las décadas del treinta y cuarenta del siglo XIX es superior al período de mayor estatura promedio del

Tabla 2. Estatura de soldados nacidos en Chile en el siglo XIX.

\begin{tabular}{|c|c|c|c|c|c|}
\hline $\begin{array}{c}\text { Década } \\
\text { nacimiento }\end{array}$ & Número de casos & $\begin{array}{c}\text { Estatura } \\
\text { promedio }\end{array}$ & Estatura mínima & Estatura máxima & $\begin{array}{c}\text { Desviación } \\
\text { estándar }\end{array}$ \\
\hline $\mathbf{1 8 3 0}$ & 68 & 168,8 & 141,0 & 184,1 & 8,0 \\
\hline $\mathbf{1 8 4 0}$ & 120 & 168,6 & 145,0 & 193,1 & 7,5 \\
\hline $\mathbf{1 8 5 0}$ & 200 & 166,1 & 140,0 & 182,0 & 7,3 \\
\hline $\mathbf{1 8 6 0}$ & 251 & 167,1 & 150,8 & 188,4 & 5,0 \\
\hline $\mathbf{1 8 7 0}$ & 260 & 167,3 & 140,0 & 184,0 & 5,5 \\
\hline $\mathbf{1 8 8 0}$ & 319 & 165,3 & 151,0 & 188,0 & 5,1 \\
\hline $\mathbf{1 8 9 0}$ & 325 & 166,4 & 150,0 & $\mathbf{1 9 3 , 1}$ & 5,6 \\
\hline Total & $\mathbf{1 , 5 4 3}$ & $\mathbf{1 6 6 , 7}$ & $\mathbf{1 4 0 , 0}$ & $\mathbf{6 , 2}$ \\
\hline
\end{tabular}

Fuente: AHE.

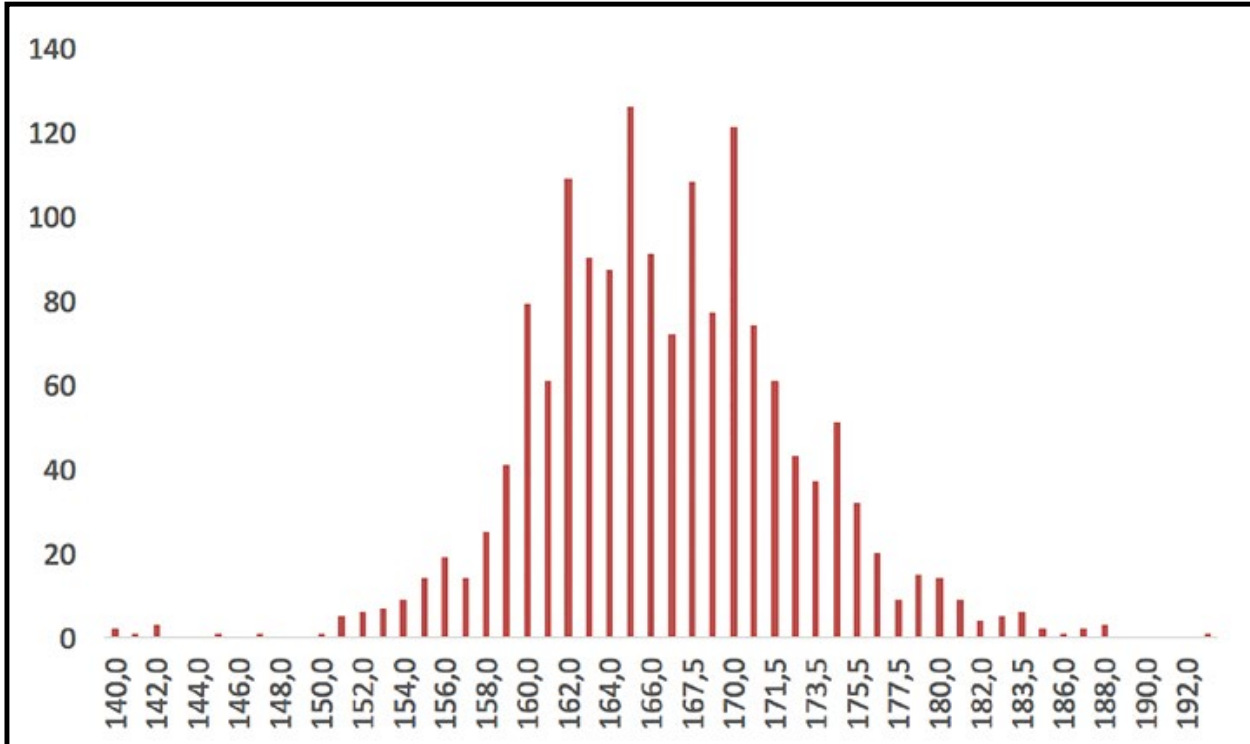

Figura 2. Frecuencia de las estaturas reportadas en nuestra muestra: siglo XIX (en cm). Fuente: AHE. 


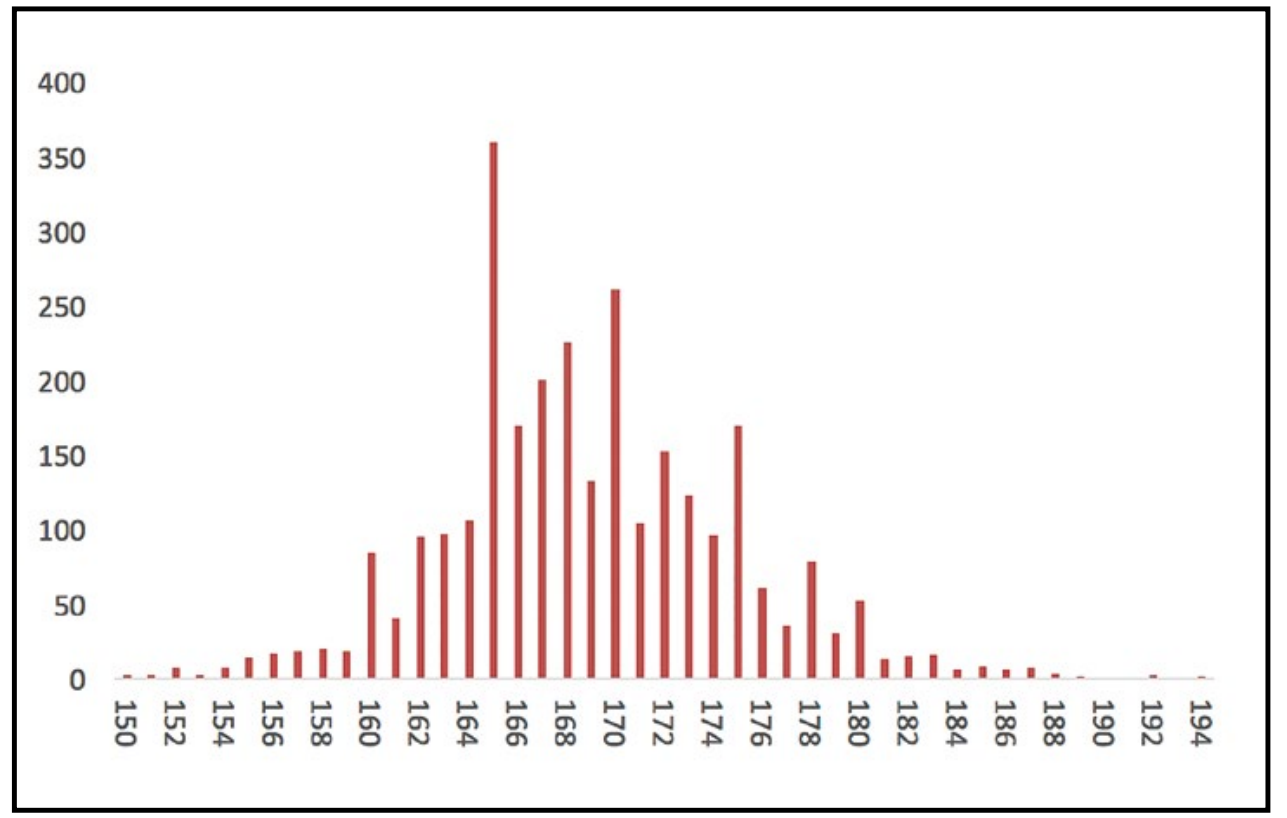

Figura 3. Frecuencia de las estaturas reportadas en nuestra muestra: siglo $\mathrm{XX}(\mathrm{en} \mathrm{cm})$. Fuente: AHE.

período colonial (Tabla 1), pero cae significativamente con posterioridad, ${ }^{19}$ sobre todo en los años 1850. Un chileno de bajos ingresos nacido a fines del siglo XIX tenía una estatura muy similar a la de uno nacido a fines del siglo XVIII.

\section{Siglo $X X$}

$\mathrm{Al}$ igual que en los dos períodos anteriores, para el siglo XX hemos realizado la misma inspección visual de los datos, como punto de partida (Figura 3). La misma nos muestra que, a diferencia del período colonial, pero similar al siglo XIX, la frecuencia de datos por estatura se comporta en forma muy parecida a una distribución normal, excepto por la inusual cantidad de datos en el valor $165 \mathrm{~cm}$, que operó como una estatura mínima de jure. No obstante lo anterior, se verifican una gran cantidad de observaciones por debajo de este número, lo que hace evidente que no se cumplió con este requerimiento a cabalidad, tal como ocurrió durante buena parte del

19 Cabe destacar que un fenómeno similar se observó en los Estados Unidos entre los años 1830 y los 1870 (Steckel, 1995). siglo XIX (y de hecho sabemos que la estatura mínima por largos período del siglo estaba por debajo de los $165 \mathrm{~cm}$ ). Vale decir, la truncación de los datos a la izquierda es bastante menor que para el período colonial, y por lo tanto tenemos menos problemas estadísticos que antes del período de la Independencia, aunque el heaping en torno a la estatura mínima es más acentuado que durante el siglo XIX, no así para los $170 \mathrm{~cm}$. Más importante que esto, cabe destacar que se observa una clara tendencia creciente en la estatura promedio por décadas, que para la totalidad del período es de $168,8 \mathrm{~cm}$ (Tabla 3). El siglo XX se inicia con una estatura promedio cercana a $166 \mathrm{~cm}$ y termina en torno a los $172 \mathrm{~cm},{ }^{20}$ es decir, un incremento acumulado de casi $6 \mathrm{~cm}$ en 90 años, menos espectacular que el caso colombiano ya comentado, pero igualmente destacable.

20 Para fines de los años 1990, un estudio de la Asociación Chilena de Seguridad estimó en $169 \mathrm{~cm}$ la estatura de trabajadores adultos chilenos en la región Metropolitana (nacidos en décadas anteriores), no muy distante de nuestras estimaciones para los ańos 1950-1970. La muestra consistió en 385 hombres, con una edad promedio de 35 ańos, principalmente de estratos socioeconómicos medio-bajos (Cárcamo y Almagia, 2000). 
Tabla 3. Estatura de soldados nacidos en Chile en el siglo XX, 1900-1989.

\begin{tabular}{|c|c|c|c|c|c|}
\hline $\begin{array}{c}\text { Década } \\
\text { nacimiento }\end{array}$ & Número de casos & $\begin{array}{c}\text { Estatura } \\
\text { promedio }\end{array}$ & Estatura mínima & Estatura máxima & $\begin{array}{c}\text { Desviación } \\
\text { estándar }\end{array}$ \\
\hline $\mathbf{1 9 0 0}$ & 385 & 165,9 & 150,0 & 188,0 & 6,0 \\
\hline $\mathbf{1 9 1 0}$ & 347 & 167,2 & 154,0 & 187,0 & 5,4 \\
\hline $\mathbf{1 9 2 0}$ & 299 & 167,4 & 155,0 & 180,0 & 4,5 \\
\hline $\mathbf{1 9 3 0}$ & 299 & 168,8 & 152,0 & 186,0 & 5,3 \\
\hline $\mathbf{1 9 4 0}$ & 344 & 168,0 & 155,0 & 185,0 & 5,1 \\
\hline $\mathbf{1 9 5 0}$ & 255 & 169,3 & 152,0 & 194,0 & 5,6 \\
\hline $\mathbf{1 9 6 0}$ & 291 & 170,8 & 160,0 & 188,0 & 5,2 \\
\hline $\mathbf{1 9 7 0}$ & 313 & 171,5 & 152,0 & 192,0 & 6,1 \\
\hline $\mathbf{1 9 8 0}$ & 321 & 171,8 & 156,0 & 192,0 & $\mathbf{1 9 4 , 0}$ \\
\hline Total & $\mathbf{2 , 8 5 4}$ & $\mathbf{1 6 8 , 8}$ & $\mathbf{1 5 0 , 0}$ & 5,9 \\
\hline
\end{tabular}

Fuente: AHE.

\section{Composición étnica y por regiones}

Aparte de los datos agregados que hemos presentado por década, también resulta interesante conocer la información por composición étnica (o clasificación racial). De los 6.183 casos disponibles, pudimos obtener información sobre color de la piel para 4.937 casos. De éstos, un 39\% son blancos; un 52\%, morenos (mestizos de piel oscura); un $8 \%$, trigueños (mestizos, tostados), ${ }^{21}$ mientras que los negros representan solo un $0,4 \%$. Para el período colonial, $49 \%$ eran blancos; $17 \%$, morenos; $33 \%$, trigueños, y $2 \%$, negros. Para el total del Obispado de Santiago (entre Copiapó y el Maule), en 1778-1779, único período para el cual disponemos de datos comparables, la proporción de españoles dentro de la población total, que puede aproximarse a blancos, era de 68\% (Cussen, 2016). La estatura promedio más alta es la del grupo "blancos" (Tabla 4), con 168,4 $\mathrm{cm}$ en promedio, seguido de morenos $(167,8 \mathrm{~cm})$ y trigueños $(167,2 \mathrm{~cm})$. Aun cuando es cierto que los blancos están por encima de las otras categorías, también es cierto que la diferencia con los otros grupos no es contundente. De hecho, son apenas 0,6 $\mathrm{cm}$ con respecto a los morenos, lo que hablaría de

21 Morenos y mestizos bien podrían agruparse en una sola categoría, toda vez que ambos grupos son mestizos (Rojas, 2010), pero preferimos respetar la clasificación en la fuente original. una desigualdad en bienestar biológico por categoría étnica menor a la observada en otros países latinoamericanos, al menos para el estrato social analizado.

Respecto de la estatura por regiones de nacimiento de los conscriptos, la Tabla 5 contiene estatura promedio por década, para aquellas regiones donde se tienen más de 20 datos por decenio. Hemos agrupado los datos según las clasificaciones típicas de la historiografía chilena: sur (desde Concepción hacia el sur), norte (desde la actual cuarta región al norte), valle central (entre el sur y el norte, excluido Santiago) y Santiago, similar a lo hecho para México (López-Alonso, 2015, usó cuatro regiones). Los datos muestran que para el período colonial el grueso de la muestra proviene del sur del país (54\%), seguido del valle central, por lo tanto principalmente de zonas rurales. En el siglo XIX se produce claramente un cambio en la composición de la muestra, siendo el valle central la región más representada $(58 \%$ de los datos). Para el siglo XX, la participación de Santiago (29\%), el sur (29\%) y el valle central (27\%) es muy parecida, pero el norte, antes muy poco representado, alcanza un 15\% de participación. Así, resulta claro de los datos que la población del sur presenta la menor estatura de la muestra para prácticamente todas las décadas, alternando el resto de las regiones el tope de la tabla, aunque Santiago presenta la mayor estatura promedio para la totalidad de los datos, 
Tabla 4. Estatura según composición étnica, 1730-1989.

\begin{tabular}{|l|c|c|c|c|c|}
\hline Color de piel & Frecuencia & Promedio & Min & Máx & SD \\
\hline Blanco & 1,930 & 168,4 & 140,0 & 194,0 & 6,0 \\
\hline Moreno & 2,575 & 167,8 & 140,0 & 192,0 & 6,0 \\
\hline Trigueño & 410 & 167,2 & 132,6 & 192,2 & 6,0 \\
\hline Negro & 22 & 165,0 & 156,1 & 182,0 & 5,8 \\
\hline ND & 1,246 & 167,4 & 140,8 & 189,9 & 5,1 \\
\hline Total & $\mathbf{6 , 1 8 3}$ & $\mathbf{1 6 7 , 9}$ & $\mathbf{1 3 2 , 6}$ & $\mathbf{1 9 4 , 0}$ & \\
\hline
\end{tabular}

Fuente: ANCH-CM, AHE.

Tabla 5. Estatura promedio por regiones de procedencia, 1740-1989.

\begin{tabular}{|c|c|c|c|c|c|c|c|c|c|c|}
\hline \multirow[b]{2}{*}{ Década } & \multicolumn{5}{|c|}{ Frecuencia } & \multicolumn{5}{|c|}{ Estatura promedio } \\
\hline & Norte & Santiago & Sur & $\begin{array}{c}\text { Valle } \\
\text { central }\end{array}$ & Total & Norte & Santiago & Sur & $\begin{array}{c}\text { Valle } \\
\text { central }\end{array}$ & Total \\
\hline 1740 & & 1 & 64 & 11 & 76 & & & 167,2 & & 167,2 \\
\hline 1750 & 1 & 4 & 117 & 49 & 171 & & & 167,2 & 168,9 & 167,8 \\
\hline 1760 & 1 & 9 & 301 & 203 & 514 & & & 167,8 & 168,1 & 168,0 \\
\hline 1770 & 2 & 20 & 385 & 204 & 611 & & 168,1 & 166,8 & 167,7 & 167,2 \\
\hline 1780 & 1 & 5 & 59 & 143 & 208 & & & 166,3 & 166,6 & 166,4 \\
\hline 1790 & 6 & 9 & 55 & 79 & 149 & & & 165,1 & 166,4 & 166,0 \\
\hline 1800 & 2 & 6 & 9 & 28 & 45 & & & & 166,7 & 165,7 \\
\hline 1810 & & & & & & & & & & \\
\hline 1820 & & & & & & & & & & \\
\hline 1830 & 3 & 13 & 15 & 37 & 68 & & & 168,7 & 168,9 & 168,8 \\
\hline 1840 & 2 & 19 & 34 & 64 & 120 & & 171,7 & 168,1 & 168,1 & 168,6 \\
\hline 1850 & 6 & 51 & 56 & 87 & 200 & & 166,3 & 166,3 & 166,1 & 166,1 \\
\hline 1860 & 14 & 57 & 42 & 134 & 251 & & 169,0 & 165,5 & 167,1 & 167,1 \\
\hline 1870 & 6 & 24 & 49 & 181 & 260 & & 166,6 & 167,2 & 167,5 & 167,3 \\
\hline 1880 & 14 & 16 & 42 & 247 & 319 & & 168,8 & 164,3 & 165,1 & 165,3 \\
\hline 1890 & 45 & 47 & 93 & 139 & 325 & 166,0 & 166,4 & 166,2 & 166,7 & 166,4 \\
\hline 1900 & 69 & 70 & 114 & 132 & 385 & 165,7 & 166,8 & 164,1 & 167,0 & 165,9 \\
\hline 1910 & 87 & 54 & 110 & 96 & 347 & 167,0 & 168,5 & 166,3 & 167,7 & 167,2 \\
\hline 1920 & 68 & 66 & 79 & 86 & 299 & 167,0 & 166,9 & 167,4 & 168,2 & 167,4 \\
\hline 1930 & 57 & 90 & 86 & 66 & 299 & 169,6 & 168,9 & 168,3 & 168,6 & 168,8 \\
\hline 1940 & 57 & 89 & 104 & 90 & 344 & 169,6 & 168,8 & 166,5 & 167,9 & 168,0 \\
\hline 1950 & 11 & 91 & 89 & 64 & 255 & & 171,0 & 168,2 & 168,5 & 169,3 \\
\hline 1960 & 20 & 138 & 61 & 68 & 291 & 169,5 & 171,1 & 170,1 & 170,8 & 170,8 \\
\hline 1970 & 28 & 103 & 81 & 96 & 313 & 172,8 & 172,2 & 170,1 & 171,5 & 171,5 \\
\hline 1980 & 33 & 124 & 93 & 69 & 321 & 171,6 & 172,5 & 171,4 & 171,4 & 171,8 \\
\hline Total & 533 & 1,106 & 2,138 & 2,373 & 6,171 & 167,8 & 169,4 & 167,2 & 167,7 & 167,9 \\
\hline
\end{tabular}


y en ocho décadas de los 15 decenios entre 1840 y 1980. El análisis de regresión de la Tabla 6 también confirma que Santiago ostenta la población más alta y el sur la más baja.

\section{Análisis de regresión para la totalidad del período}

La Tabla 6 contiene un análisis de regresión para la totalidad del período estudiado, por década de nacimiento, con controles según región de procedencia y edades entre 17 y 21 ańos (similar a lo realizado por López Alonso, 2015). La magnitud y signo de los coeficientes se ajusta a las variaciones esperadas entre décadas, además de confirmar la calidad de nuestros datos. Los cambios interdécadas son relativamente moderados. En otros estudios para otros países, raramente la estatura promedio entre una década y otra varía más de $3 \mathrm{~cm}$ (Challú, 2010), y en nuestro caso hay una sola variación por sobre los 2 $\mathrm{cm}$, entre los años 1850 y los 1840 , dando fiabilidad a la muestra. La tabla también pone de manifiesto que los soldados de la muestra experimentaron crecimiento en particular hasta los 18 años.

Basados en los datos de la Tabla 6, hemos representado gráficamente la estatura promedio estimada por década (Figura 4), con intervalos de confianza al 95\% (IC-a e IC-b), confirmando fehacientemente la tendencia decreciente para fines del período colonial y la segunda mitad del siglo XIX, así como la tendencia creciente para el siglo XX.

\section{Discusión de los resultados}

Como ya mencionamos en la Introducción, hasta muy recientemente la contribución que podía hacer la historia económica a discusiones sobre niveles de vida y desigualdad en la era colonial era bastante limitada, en particular debido al carácter fragmentario de la evidencia cuantitativa disponible (Salvatore et al., 1998; Baten y Carson, 2010). Afortunadamente, desde los años 1990, diversos cientistas sociales han comenzado a documentar y analizar las raíces históricas de la pobreza y la desigualdad de América Latina (ver, por ejemplo, Baltzer y Baten, 2008). En un artículo pionero, y bastante provocador (partiendo por su título: Neither so low nor
Tabla 6. Determinantes de la estatura, c. 1730-1989: análisis de regresión (OLS).

\begin{tabular}{|c|c|c|c|}
\hline Variable & Coeficiente & $\begin{array}{c}\text { Error } \\
\text { estándar }\end{array}$ & $p$ \\
\hline $1730-1740$ & 0,04 & 1,19 & 0,98 \\
\hline 1750 & 0,03 & 1,14 & 0,98 \\
\hline 1760 & 0,15 & 1,10 & 0,89 \\
\hline 1770 & $-0,59$ & 1,10 & 0,59 \\
\hline 1780 & $-1,52$ & 1,14 & 0,18 \\
\hline 1790 & $-1,99$ & 1,15 & 0,08 \\
\hline $1800-1820$ & Referencia & & \\
\hline 1830 & 1,09 & 1,38 & 0,43 \\
\hline 1840 & 0,80 & 1,27 & 0,53 \\
\hline 1850 & $-2,00$ & 1,19 & 0,09 \\
\hline 1860 & $-1,09$ & 1,17 & 0,35 \\
\hline 1870 & $-0,84$ & 1,13 & 0,46 \\
\hline 1880 & $-2,69$ & 1,11 & 0,02 \\
\hline 1890 & $-1,75$ & 1,12 & 0,12 \\
\hline 1900 & $-2,24$ & 1,12 & 0,05 \\
\hline 1910 & $-0,84$ & 1,11 & 0,45 \\
\hline 1920 & $-0,65$ & 1,11 & 0,56 \\
\hline 1930 & 0,72 & 1,11 & 0,52 \\
\hline 1940 & 0,02 & 1,11 & 0,99 \\
\hline 1950 & 1,22 & 1,13 & 0,28 \\
\hline 1960 & 2,41 & 1,11 & 0,03 \\
\hline 1970 & 3,40 & 1,12 & 0,00 \\
\hline 1980 & 3,72 & 1,12 & 0,00 \\
\hline Norte & $-0,78$ & 0,29 & 0,01 \\
\hline Sur & $-1,43$ & 0,23 & 0,00 \\
\hline Valle Central & $-0,58$ & 0,23 & 0,01 \\
\hline Santiago & Referencia & & \\
\hline 17 & $-2,23$ & 0,48 & 0,00 \\
\hline 18 & $-0,19$ & 0,29 & 0,52 \\
\hline 19 & 0,27 & 0,28 & 0,33 \\
\hline 20 & $-0,48$ & 0,21 & 0,02 \\
\hline 21 & $-0,32$ & 0,24 & 0,17 \\
\hline Constante & 168,97 & 1,08 & 0,00 \\
\hline Observaciones & 6183 & & \\
\hline $\mathrm{R}^{\wedge} 2$ & 0,104 & & \\
\hline
\end{tabular}




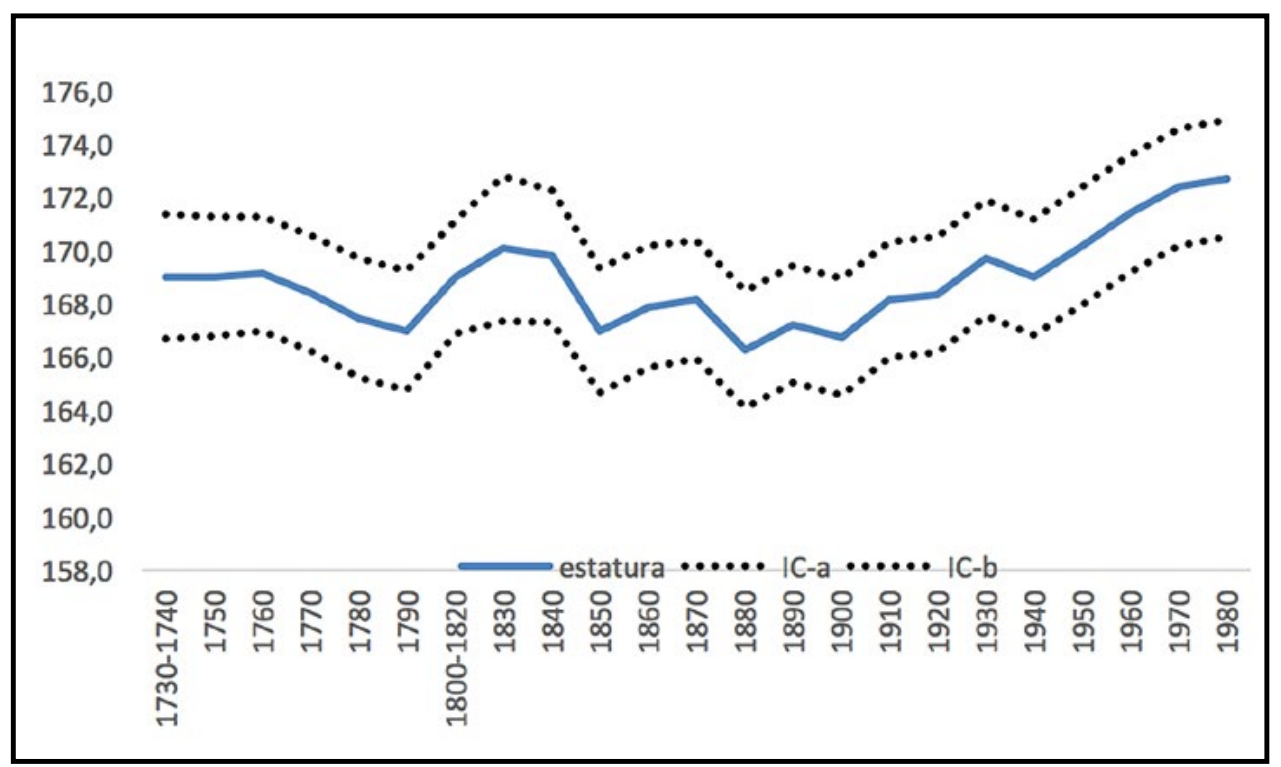

Figura 4. Promedio estimado de la estatura con intervalos de confianza (IC) al 95\%.

Fuente: Tabla 6.

so short: wages and heights in Bourbon Spanish America from an international comparative perspective), Dobado y García (2014) sostienen, como una novedad, que los salarios reales del grueso de la población hispanoamericana no eran tan bajos como creíamos, como tampoco lo era la estatura de la población. Concluyen dichos autores que los niveles de vida de la población de Hispanoamérica no habrían sido menores que los del resto del mundo, incluyendo Europa continental, y que la divergencia en niveles de vida entre nuestra región y Europa desarrollada comenzó con posterioridad a la Independencia. Lamentablemente, no aportan información para Chile, carencia que subsanamos en la sección precedente.

La alta estatura que encontramos para el período colonial en Chile no es del todo sorprendente. Bien es sabido que, por ejemplo, previo al crecimiento económico moderno del mundo desarrollado, aquellas sociedades que eran autosuficientes en oportunidades alimentarias, que vivían en tierras productivas y con baja densidad poblacional, tendían a ser de una estatura relativamente alta (Komlos, 2004). El caso chileno colonial cumple justamente con estas características, y además presenta similitudes con el caso argentino, arriba descrito. Nunca después el país gozó de tan baja densidad poblacional, haciendo uso de las tierras más fértiles, lo que habría ayudado a reducir la propagación de enfermedades, al menos si se compara con sociedades del siglo XX (Steckel, 1995), y producir alimentos con menos esfuerzo físico. Asimismo, investigaciones recientes han constatado que, por un lado, en Chile colonial el consumo de legumbres y carnes era muy generalizado (LlorcaJańa y Navarrete, 2015), este último particularmente alto, en torno a los 80 kilos per cápita por año (unos 220 gramos diarios), debajo de Argentina, pero muy por encima del resto de los países para los que se dispone de información (Martínez, 2016). En comparación con otros períodos, a principios del siglo XX las clases populares chilenas consumían unos 50 gramos per cápita de carne por día, cargando la dieta a cereales (trigo) y papas. Para los períodos 19121931 y 1928-1937 este consumo habría aumentado a unos 91 y 95 gramos diarios, respectivamente, y a mediados de la década del cuarenta se estimaba en unos 113 gramos, aún muy por debajo de la época colonial (Santa María, 1941; Cruz-Coke, 1928; Yáñez, 2017; Deichler, 2016; Musalem, 1950). Lamentablemente, la importancia del trigo y las papas dentro de la dieta de los chilenos seguía siendo muy determinante en las primeras décadas del siglo XX (Mardones, 1935; Santa María, 1935). 
Con todo, se ha constatado que los salarios reales de la población chilena a fines del período colonial estaban por sobre el nivel de subsistencia, permitiendo una buena ingesta proteica y calórica (Llorca-Jaña y Navarrete, 2015).

Respecto de la caída en la estatura que se observa en los años de la década de 1850, cabe destacar que dicha década estuvo marcada por dos guerras civiles en Chile (1851 y 1859), por lo que no es de extrañar que ambas hayan impactado negativamente en el bienestar biológico de la población. Efectivamente, la guerra civil de 1891 fue aún muy convulsiva. Asimismo, considerando que hay una gran relación entre salud y nutrición (López Alonso, 2015), cabe destacar que igualmente dañinas para esta década, y las siguientes del siglo XIX, fueron las epidemias de tuberculosis (que antes de la primera mitad del siglo XIX poco impacto habían tenido en Chile), ${ }^{22}$ las epidemias de viruela de 1864, 1868, 1872, 1876 y 1880 (Illanes, 1993), ${ }^{23}$ la gran epidemia de cólera que azotó a Chile entre 1886 y 1888 (provocando la muerte de 24 mil personas), epidemias de tifus (1865), epidemia de influenza en 1892-3 (que costó la vida de 33 mil personas) y la epidemia de sarampión de fines de siglo (Cruz-Coke, 1995; Aguilera y Zúñiga, 2006). Todas estas grandes plagas comenzaron a ser más dañinas que en el período colonial debido a la creciente urbanización (caldo de cultivo para la rápida propagación de epidemias). Con todo, el último cuarto del siglo XIX es visto como un período de hacinamiento, hambre, enfermedad, marginalidad y miseria. Familias enteras vivían en una sola pieza, por donde normalmente circulaba

22 La tuberculosis en particular estaba muy asociada a deficiencias alimentarias, debido a la ingesta deficiente de prótidos (proporcionados por la carne, leche, huevos y queso), lípidos y vitaminas A y D, y la consecuente falta de resistencia a enfermedades (Mardones, 1935; González, 1935; Santa María, 1935).

23 Estas epidemias de viruela se produjeron a pesar de las campañas de vacunación contra la enfermedad. El éxito de las mismas dependía de la calidad de la vacuna, de la revacunación oportuna y de la universalidad de su aplicación. Al no ser obligatoria la vacunación durante varias décadas, se produjeron muchos brotes por largos períodos, debido a la pasividad de los gobiernos de turno (MacClure, 2012). Recién en 1918 se estableció la vacunación obligatoria y la viruela fue erradicada en las primeras décadas del siglo XX (Cabrera, 2008; Zárate, 2008). una acequia que acarreaba todo tipo de desechos (Illanes, 1993; Fernández, 2015). Son justamente estas precarias condiciones de vida que sentaron las bases de la denominada "Cuestión Social" en Chile.

Respecto de la aplicación de la vacuna contra la viruela, en 1812 se creó la Junta Nacional de Vacunas, en la Patria Vieja, posteriormente reactivada por O’Higgins en 1817 (Cruz-Coke, 1995; Mac-Clure, 2012). Finalmente, el Instituto de Vacuna Animal, encargado de producir las vacunas, se crea en 1887 (Cabrera, 2008).

La caída en la estatura en las décadas centrales del siglo XIX es también consistente con un aumento en la desigualdad del ingreso personal en Chile durante este período. Rodríguez (2017) ha constatado recientemente que, durante los años 1850, 1860, 1870, el coeficiente Gini del ingreso personal aumentó y estuvo en uno de los niveles más altos de la historia republicana. Por su parte, Steckel (1995) ha dejado claro que mayor desigualdad normalmente va asociado a menor estatura poblacional.

Asimismo, Mac-Clure (2012) ha estimado que las tasas de mortalidad de Chile, sobre todo de Santiago y Valparaíso en las décadas de 1850, 1860 y 1870, eran considerablemente más altas que las de buena parte de Europa y Argentina, impactando principalmente a las clases más desprotegidas, en particular a los niños. ${ }^{24}$ Mala alimentación (incluyendo ingesta de alimentos en mal estado), ${ }^{25}$ pobre vestimenta, escasez de agua potable ${ }^{26} \mathrm{y}$ falta de higiene se citaban como los factores determinantes de esta alta mortalidad. Cronistas de la época constataron que el 'roto'

24 A modo de ejemplo, en 1896 la tasa de mortalidad de Santiago era de casi 40 por mil habitantes, mientras que la de Buenos Aires o Filadelfia era la mitad, la de Montevideo solo 16, y la de Chicago casi 14 . Solo ciudades africanas tenían una mortalidad parecida o superior a la de Santiago (Murillo, 1900).

25 La mortalidad infantil estaba altamente influenciada por casos de diarrea y disentería (Mac-Clure, 2012).

26 En ciudades como Santiago, las clases populares se abastecían de agua para consumo humano en canales y acequias, un agua apta para riego, pero que en ningún caso era potable. En Valparaíso, por su parte, en 1877 el intendente de la región culpaba a la falta de agua potable por la alta mortalidad infantil de la zona (MacClure, 2012). 
chileno de fines del XIX era bastante más bajo que el de décadas anteriores consecuencia de estas condiciones de vida (Rojas, 2010), que en buena medida estaban relacionadas con el creciente poblamiento que experimentaba el país. Al respecto, ha quedado establecido para otros países que, antes del siglo XX, el crecimiento de la urbanización estuvo asociado a caídas en estatura (Steckel, 1995). ${ }^{27}$

Concretamente, en Chile la tasa de población urbana sobre el total nacional pasó de menos de $30 \%$ en el Censo 1865 a $45 \%$ en el de 1895 , sin duda un aumento rápido y significativo (Díaz et al., 2016), que antes de la implementación de agua potable, alcantarillado (vital para eliminar residuos en zonas urbanas) ${ }^{28}$ y medidas sanitarias seguramente provocó estragos en la salud de la población, tal como ocurrió en otros países. Los problemas de salubridad de la población redundaban en elevadas tasas de morbilidad y mortalidad, así como en una alimentación deficiente (Allende, 1939). Un estudio de 1893 sobre las causas de la mortalidad infantil en Chile, realizado por dos médicos chilenos, era enfático en responsabilizar a las acequias, la falta de alcantarillado y provisión de agua potable por las altas tasas de mortalidad y morbilidad en Chile, describiendo Santiago como "una de las más insalubres ciudades del mundo" (Sierra y Moore, 1895). ${ }^{29}$ En paralelo,

27 De hecho, Steckel (1995) ha argumentado que, cuando analizamos la evolución de la estatura poblacional de un país determinado, la tasa de urbanización es un factor muy importante a tener en cuenta.

28 Respecto del alcantarillado, en el principal centro urbano nacional, Santiago, hubo un rezago considerable en la implementación de un sistema sanitario de eliminación de residuos (en reemplazo del precario e insalubre sistema de acequias establecido en la época colonial), al menos si se compara con Europa y otras ciudades de la región como Buenos Aires. Tal falencia explicaba en buena medida la alta tasa de mortalidad de la urbe. A consecuencia de esto, la población estaba en permanente contacto con aguas infestadas, excremento humano y animal, entre otros residuos, que provocan malos olores y miasmas. Esto llevó además a la proliferación de moscas, portadoras de infecciones intestinales que atacaban principalmente a los niños (Mac-Clure, 2012). Situación similar se observaba en otras ciudades chilenas como Chillán y Curicó.

29 Recién en la década de 1860 se inició el abastecimiento de agua potable en Santiago a través de cañerías, pero en un principio solo a las clases más pudientes: una minoría. Gradualmente, pero con mucha lentitud, el ser- antes de 1870 no existía ningún sistema público de salud en Chile. Entre 1870 y principios del siglo XX recién se comienza a configurar, lentamente, un sistema público de salud nacional (Urriola, 2009)..$^{30}$

Asimismo, nuestros datos para el siglo XIX muestran ciertas fluctuaciones que merecen explicación. Al respecto, Steckel (1995) ha sido enfático en señalar que, para países europeos y americanos, lo más común antes del siglo XX es encontrar fluctuaciones y ciclos en la estatura promedio, en lugar de una tendencia secular y estable. En ausencia de políticas públicas para prevenir la transmisión de enfermedades por medio de gérmenes (i.e. aplicar la teoría de los gérmenes), o para guiar decisiones hechas por las familias, dichas fluctuaciones resultan aún menos sorprendentes (Steckel, 1995). Los grandes avances en la historia de la medicina mundial comenzaron a tener efecto, gradualmente, entre los años 1850 y la Primera Guerra Mundial, cuando se aportó evidencia científica sobre la teoría de los gérmenes y la existencia de bacterias, la importancia de la antisepsia y la asepsia, fomentando mejores hábitos de limpieza en la población, aunque solo gradualmente (Mokyr y Stein, 1996).

Respecto de la dieta de los chilenos durante el siglo XIX, los estudios clásicos sobre la salud y medicina en Chile, lamentablemente, no han aportado antecedentes básicos sobre el estado nutricional de la población del país (Yáñez, 2016 y 2017; Aguilera y Zúñiga, 2006), e igual cosa aplica para buena parte del XX. Investigaciones futuras deberían abocarse a determinar con mayor precisión la ingesta calórica y proteica de la población, en particular el consumo promedio de carnes, lácteos y legumbres, tan determinantes en la estatura (Mardones, 1935). Dicho esto, la poca evidencia disponible ha constatado que el bajo consumo de leche, ${ }^{31}$ legumbres

vicio fue ampliado para incluir al resto de la población (Mac-Clure, 2012; Fernández, 2015).

30 Institucionalmente, se emiten diversos reglamentos sanitarios (p.e., Ley de Policía Sanitaria de 1886, Ley de Profilaxis de 1898 y el Código Sanitario de 1918), se crea el Consejo Superior de Higiene Pública (en 1889, el pionero en la centralización de la sanidad pública en Chile), el Servicio de Higiene Pública y el Instituto de Higiene Pública (1892). Se creó además el Consejo Superior de Habitación (obrera) (Illanes, 1993).

31 No existía en Chile una producción lechera especializada, actividad más bien artesanal. La leche que se produ- 
y carne de la población chilena con menos recursos en el siglo XIX era uno de los factores centrales de las carencias nutricionales de esta población y de la alta tasa de mortalidad infantil (Zárate, 2013; Cruz-Coke, 1928) y adulta, sobre todo por tuberculosis (Mardones, 1935). No tenemos cifras exactas para el siglo XIX, pero sabemos que a principios del siglo XX el país producía y consumía muy poca leche, poca carne y escasas legumbres, mientras que el procesamiento de leche y carne en particular era deficiente, representando su consumo riesgos para la salud de la población (Deichler, 2016; Cruz-Coke, 1928; González, 1935). Por ejemplo, en la década de 1930 el país producía el equivalente a unos 50 litros al año por persona, mientras que países europeos producían entre 6 y 12 veces más que Chile en términos per cápita (Allende, 1939). ${ }^{32}$ Este bajo consumo de lácteos dio origen al denominado "Problema de la Leche" en Chile.

Con todo, parece claro que el crecimiento económico del siglo XIX no se tradujo en mejores niveles de vida biológicos para el grueso de la población, sino más bien para una élite económica que acaparó rentas. En efecto, la segunda mitad del siglo XIX se visualiza como un período negativo en el bienestar biológico de Chile, lo que resulta paradójico toda vez que las ultimas décadas de este siglo coinciden con el auge salitrero y el consiguiente boom exportador. Sin embargo, varios países latinoamericanos presentan similar comportamiento, como vimos en la segunda sección: en períodos de boom exportador y crecimiento económico, el bienestar nutricional de la población empeora, algo similar a lo ocurrido en aquellos países que se industrializaron, justamente cuando el crecimiento económico se aceleró.

cía era más bien un producto secundario de la actividad ganadera (Aguilera y Zúñiga, 2006).

32 A principios de la década del cuarenta se estimaba que la población chilena consumía menos de la mitad de la leche diaria recomendada por el Comité de la Liga de las Naciones (Scriggie, 1942). Una de las razones de la baja ingesta de carne y leche era el alto precio relativo de estos productos en el mercado chileno (González, 1935). En efecto, famosa es la Huelga de la Carne de 1905, gatillada justamente por el alto precio de este producto, y los Mítines del Hambre de 1919. Algo similar ocurrió en México durante el Porfiriato (López Alonso, 2015).
Posteriormente, el aumento de la estatura de la población en el siglo XX chileno no es de sorprender. ${ }^{33} \mathrm{El}$ mismo coincide con progresos en la distribución del ingreso personal en las décadas de 1930, 1940, 1950 y 1960 (Rodríguez, 2017); con mejores hábitos de limpieza de la población (tanto en la vida cotidiana como para manipular alimentos); con la propagación del higienismo en Chile; con la introducción de antibióticos en la salud estatal (en particular la difusión de la penicilina) desde la década del treinta (y de vacunas obligatorias $)^{34}$ para tratar enfermedades y las consecuentes mejoras en indicadores de salud (Steckel, 1995; Mokyr y Stein, 1996; Zárate, 2013;); con la construcción de los primeros hospitales infantiles en Chile y el desarrollo de la pediatría en el país (Cruz-Coke, 1995; Deichler, 2016), así como con un aumento sostenido en el número de profesionales del sector salud y de una consecuente profesionalización médica en Chile. ${ }^{35}$ Como parte de este proceso, la salud pasa de ser un objeto de interés privado-individual (dependiendo el grueso de la población de la caridad), a uno público-colectivo, con gran participación del Estado (Illanes, 1993; Zárate, 2008). ${ }^{36}$

Si a fines del siglo XIX en Chile la esperanza de vida al nacer era de poco más de 30 años, a mediados del siglo XX ya superaba los 55 años y a principios de la séptima década, los 70 años (Díaz et al., 2016). También aconteció, como en otros países, lo que se ha denominado "revolución de la mortalidad" (LópezAlonso, 2015). En efecto, la mortalidad infantil en el

33 Dicho esto, en la primera década del siglo XX se observó una caída en la estatura promedio. Esta década estuvo marcada por la fiebre tifoidea, que cobró la vida de 25 mil chilenos entre 1905 y 1910.

34 En la primera mitad del siglo se introduce en Chile la vacuna BCG contra la tuberculosis (López, 2015; Urriola, 2009). Sin embargo, en un principio la vacunación no era ni obligatoria ni universal, por lo que se produjeron muchas epidemias (Sierra y Moore, 1895).

35 En 1854 se estima que en Chile había solo 129 médicos, uno por cada 12 mil habitantes. En 1895 esta cifra había disminuido a un médico por unos 3.300 habitantes, mejorando este ratio hasta 1.870 habitantes por médico en 1940 .

36 Cabe destacar que el Servicio Nacional de Salud se creó en 1952, agrupando diversas instituciones ya existentes. Su cobertura era casi universal, y gracias a sus funciones la población chilena, en pocas décadas, comenzó a gozar de indicadores de salud comparables con países con niveles de ingreso mucho más altos que el chileno (Illanes, 1993; Molina, 2009). 
período 1907-1909 fue de casi 285 por mil nacidos, ${ }^{37}$ cayendo aceleradamente a partir de los años cuarenta hasta menos de 100 en los sesenta y poco más de 20 en la década de 1980 (Díaz et al., 2016). La cobertura de agua potable y de alcantarillado también aumentó de manera espectacular, sobre todo a partir de los años sesenta, gracias a innovaciones tecnológicas más bien propias de la ingeniería civil. ${ }^{38}$ Alrededor de 1930 solo el 39\% de la población chilena vivía en poblaciones con obras de saneamiento (alcantarillo y agua potable). A fines de los ańos setenta el $90 \%$ de la población urbana ya tenía servicio de agua potable, llegando a 99\% a mediados de los ańos noventa (Allende, 1939; Díaz et al., 2016).

En educación, la tasa de analfabetismo en mayores de 15 años pasó de $50 \%$ a principios del siglo a solo $8 \%$ en los ochenta, los años de escolaridad promedio de poco más de dos a más de ocho en igual período, mientras que el índice de capital humano casi se duplicó entre inicios del siglo y la década de 1980 (Díaz et al., 2016). Los salarios reales también experimentaron un aumento significativo a lo largo de la mayor parte del siglo XX (Díaz et al., 2016).

Finalmente, se implementaron intensas campañas para promover $-y$ alargar- el amamantamiento, ${ }^{39}$ así como el consumo y distribución de leche de vaca (en diversos formatos: p.e., condensada, evaporada, desecada) en mujeres embarazadas, lactantes y niños, en programas como las Gotas de Leche (que brindaba atención y educación a madres y lactantes desde 1901) y el servicio Madre y Niño de la Caja del Seguro Obligatorio, promulgando incluso una ley para promover la pasteurización de la leche (1930). Asimismo, en 1937 se crea el Consejo Nacional de Alimentación para mejorar la nutrición de la población

37 Una de las más altas del mundo en este período (Deichler, 2016; Yáńez, 2007; Murillo, 1900). Esto llevó a la creación del Patronato Nacional de la Infancia, para combatir dicho flagelo (Deichler, 2016).

38 Similar fenómeno se observó en otros países latinoamericanos, tales como México (López-Alonso, 2015).

39 Se perseguía dejar claramente establecido que la leche materna era el mejor alimento para los bebés. Gracias a estas campañas, la lactancia materna alcanzó amplios niveles de transversalidad en Chile durante el siglo XX. Esto devino en mejor dieta para los lactantes, pero también en mejores defensas y en una reducción de enfermedades intestinales en infantes, todo lo cual redujo de manera importante la mortalidad infantil (Zárate, 2013). chilena, con marcado acento en promover la producción lechera y el consumo de productos lácteos. Posteriormente el Estado creó el programa Servicio de Desayuno Escolar, los Bares Lácteos y planes de fomento lechero (Aguilera y Zúñiga, 2006).

En general, mejoró mucho la información respecto de la higiene alimentaria, el tipo de alimentos más apropiados para infantes y embarazadas, incluido el consumo de alimentos industriales, menos propensos a su descomposición en períodos en los que los sistemas de refrigeración (tanto en hogares como en transporte) no eran de uso masivo, y del valor nutricional de los alimentos (Scriggie, 1942; Zárate, 2013; Deichler, 2016). ${ }^{40}$ Son justamente este tipo de factores los que han explicado el aumento de la estatura en buena parte de los países occidentales (Steckel, 1995). Al respecto, y como en México (López-Alonso, 2015), lo más probable es que el aumento en estatura del siglo XX se deba fundamentalmente a avances en salud, higiene y educación, más que en nutrición.

\section{Comparación con otras regiones}

Los datos arriba mencionados aportan mayores antecedentes a nuestro análisis si se comparan con otras regiones del mundo. ${ }^{41} \mathrm{Al}$ respecto, una pregunta obvia emerge: ¿Cómo se comparan nuestros resultados con otros países de América Latina o del mundo desarrollado? La Tabla 4 resume la información disponible para diversos países seleccionados, desde la década de 1740 a la de 1980 . Respecto del período colonial, cabe destacar que la estatura de los soldados chilenos es de las más altas de la muestra para América española, superando ampliamente a México, Brasil y Maracaibo, ${ }^{42}$ aunque se encuentra

40 La forma en que se alimentaba la población era un tema crucial, toda vez que se estimaba que las afecciones digestivas eran una de las principales causas de mortalidad infantil en Chile, "otorgándole cuidados, salud, enseñanzas y alimentación a un porcentaje importante de mujeres y niños de los sectores populares" (Deichler, 2016). Un estudio de 1893 estimaba que un $40 \%$ de las muertes en Chile se producía por desórdenes del aparato digestivo (Sierra y Moore, 1895).

41 Toda comparación entre países en esta sección es realizada en términos brutos, como los datos presentados en las Tablas 1,2 y 3.

42 Los datos de Maracaibo están disponibles en el artículo de Dobado (2015). No fueron incluidos aquí por razo- 
Tabla 7. Estaturas promedios de Chile y países seleccionados, décadas entre 1740 y 1980.

\begin{tabular}{|c|c|c|c|c|c|c|c|c|c|c|}
\hline $\begin{array}{c}\text { País / } \\
\text { Década } \\
\text { naci- } \\
\text { miento }\end{array}$ & Holanda & $\begin{array}{l}\text { Reino } \\
\text { Unido }\end{array}$ & EEUU & Suecia & España & Argentina & México & Brasil & Colombia & Chile \\
\hline 1740 & & 169,5 & & 169,5 & 163,3 & & 165,0 & & & 167,2 \\
\hline 1750 & & 169,8 & 172,2 & 168,3 & 163,6 & & 163,8 & & & 167,8 \\
\hline 1760 & 169,5 & 169,8 & & 168,0 & 163,2 & & 164,0 & & & 168,0 \\
\hline 1770 & 168,6 & 168,3 & 172,8 & 167,0 & 164,3 & 170,3 & 163,8 & & & 167,2 \\
\hline 1780 & 165,6 & 167,5 & 173,1 & 166,8 & 163,3 & 168,2 & 162,5 & & & 166,4 \\
\hline 1790 & 164,9 & 166,0 & 172,9 & 167,8 & & 168,0 & 162,5 & & & 166,0 \\
\hline 1800 & & & & 167,1 & & 168,0 & 162,1 & & & 165,7 \\
\hline 1810 & 166,0 & 169,7 & & & & 168,8 & 161,3 & 164,3 & & \\
\hline 1820 & 165,1 & 169,1 & 172,2 & & & 169,9 & 160,4 & 164,3 & & \\
\hline 1830 & 164,2 & 166,7 & 173,5 & 168,1 & 161,0 & 170,9 & 160,4 & 164,8 & & 168,8 \\
\hline 1840 & 164,5 & 166,5 & 172,2 & 167,9 & 163,7 & 169,6 & 162,5 & 164,6 & & 168,6 \\
\hline 1850 & 165,3 & 165,6 & 171,1 & 168,4 & 162,5 & 168,2 & 163,4 & 164,5 & & 166,1 \\
\hline 1860 & 166,5 & 166,6 & 170,6 & 169,3 & 162,7 & 167,4 & 162,9 & 165,0 & & 167,1 \\
\hline 1870 & 167,1 & 167,2 & 171,1 & 170,3 & 162,6 & 167,6 & 163,7 & 166,5 & 161,1 & 167,3 \\
\hline 1880 & 168,5 & 168,0 & 169,5 & 171,2 & 163,9 & 167,6 & 163,9 & 166,1 & 162,1 & 165,3 \\
\hline 1890 & 169,4 & 167,4 & 169,1 & 172,4 & 164,0 & 167,8 & 163,9 & 167,1 & 161,9 & 166,4 \\
\hline 1900 & 170,9 & 169,4 & 170,0 & 172,8 & 164,6 & 167,9 & 163,9 & 167,5 & 161,8 & 165,9 \\
\hline 1910 & 172,6 & 170,9 & 172,1 & 173,2 & 165,1 & 168,2 & 163,7 & 166,5 & 163,5 & 167,2 \\
\hline 1920 & 173,5 & 171,0 & 173,1 & 168,3 & 165,6 & 169,0 & 161,1 & 166,6 & 164,7 & 167,4 \\
\hline 1930 & 174,1 & 173,9 & 173,4 & 175,5 & 165,2 & 169,8 & 165,5 & 167,0 & 165,5 & 168,8 \\
\hline 1940 & 177,5 & 174,9 & 176,1 & 178,5 & 166,3 & 170,6 & 165,8 & 167,1 & 167,1 & 168,0 \\
\hline 1950 & 178,7 & 176,0 & 177,1 & 179,3 & 170,8 & 170,8 & 165,1 & 168,2 & 167,8 & 169,3 \\
\hline 1960 & 182,2 & 176,9 & 177,3 & 180,1 & 174,2 & & 166,4 & 169,0 & 168,5 & 170,8 \\
\hline 1970 & 182,3 & 177,1 & 178,3 & 180,0 & 175,2 & & & 171,6 & 168,9 & 171,5 \\
\hline 1980 & 182,7 & 176,8 & 179,0 & 180,4 & 175,6 & & 167,8 & 171,7 & 170,6 & 171,8 \\
\hline
\end{tabular}

Fuente: Para Chile, ANCH-CM y AHE. Para el resto de los países, https://www.clio-infra.eu/, consultado el 20.01.2017. 


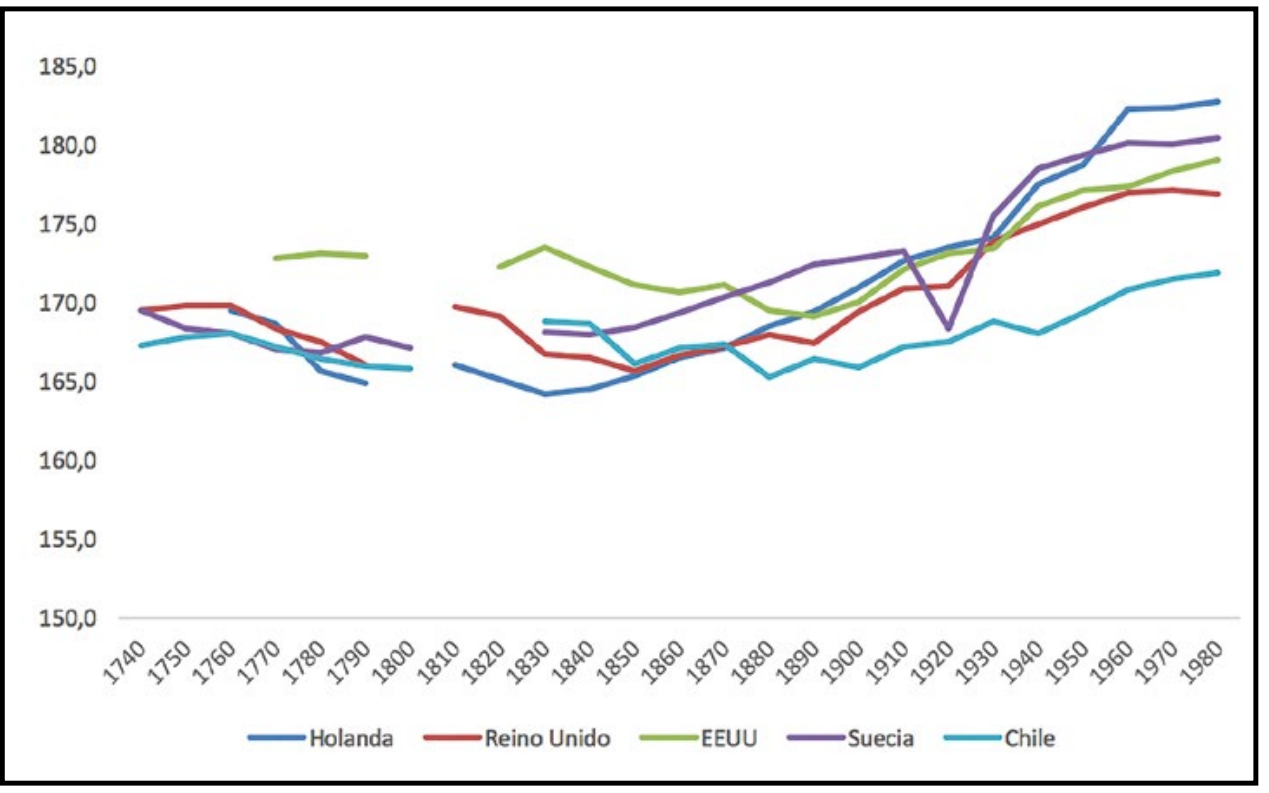

Figura 5. Estatura promedio $(\mathrm{cm})$ en Chile versus países desarrollados.

Fuente: ANCH-CM, AHE.

por debajo de los soldados de Buenos Aires. Respecto de otras regiones, también para el período colonial, la estatura de los soldados chilenos estaba bien por debajo de la de los británicos y norteamericanos, pero por encima de los de España, Baviera, Francia y Lombardía, ${ }^{43}$ y en un nivel similar a los suecos y holandeses. Vale decir, antes de la Independencia, los soldados chilenos tenían una estatura bastante aceptable, dentro y fuera de la región, lo que viene a respaldar la tesis de Dobado y García (2014). Comparado con buena parte de Europa, esto podría explicarse por la baja densidad poblacional de Chile (que reducía los peligros de la transmisión de enfermedades), acceso a tierras fértiles cultivables con poco esfuerzo físico, y mejor dieta. ${ }^{44}$

Durante el siglo XIX, en el concierto regional, la estatura de los soldados chilenos sigue estando por debajo de la de los argentinos, pero se mantiene por sobre la de los mexicanos, colombianos y brasileños, aun cuando la brecha con Brasil se reduce de forma sig-

nes de espacio.

43 Los datos de Baviera, Francia y Lombardía están disponibles en el artículo de Dobado (2015).

44 Steckel (1995) da cuenta de una muy mala dieta en buena parte de Europa en la segunda mitad del siglo XVIII, resultante en una estatura media relativamente baja. nificativa (Tabla 7). Comparado con España, Chile sigue mejor en este indicador, pero empeora su posición significativamente si se compara con Suecia y Holanda, manteniéndose igualmente lejano de los Estados Unidos; no así de los británicos, producto del empeoramiento de los niveles de vida biológicos de la Gran Bretańa que se iba industrializando, fenómeno arriba comentado (Tabla 7).

Para el siglo XX, como ya dijimos, la estatura promedio de los soldados chilenos crece bastante desde mediados de la centuria, pero éste es un fenómeno generalizado en el mundo (Tabla 7). Es decir, en términos comparativos con otras regiones, lo que sucedió en Chile resulta bastante menos espectacular de lo esbozado en la sección precedente. No obstante lo anterior, la estatura de los chilenos durante este siglo se ubicó por encima de la de Brasil, México y Colombia, y se mantiene por debajo de la de Argentina. Al respecto, pudimos encontrar datos fragmentarios de consumo de leche y carne per cápita para países sudamericanos en los ańos 1930: el consumo de carne y leche promedio en Chile era superior al de todos los países para los que hay evidencia disponible, salvo Argentina y Uruguay (Musalem, 1950). Comparado con países desarrollados (Figura 5), el desempeño de Chile es poco satisfactorio: es claro que la estatura de los chilenos 
está muy por debajo de la de los suecos, británicos, holandeses y estadounidenses, y para la segunda mitad del siglo está incluso por debajo de la de los españoles, que históricamente se situaban por debajo de Chile. En otras palabras, hay una divergencia acentuada con el mundo desarrollado en los niveles de nutrición neta de los chilenos.

\section{Conclusiones}

Aun cuando nuestra muestra de estaturas de soldados chilenos, como todas las muestras que usan registros militares, está sesgada por la imposición de la estatura mínima requerida por el Ejército, Komlos (2004) y Komlos y Kin (1990) han demostrado que la tendencia de la estatura media de muestras truncadas es la misma que la tendencia subyacente de la muestra sin truncar del universo de donde proviene la muestra truncada. Vale decir, las variaciones de largo plazo que hemos constatado son perfectamente legítimas, extrapolables al grueso de la población chilena, a pesar de los problemas que hemos constatado en este artículo. No solo eso, Komlos (2004) ha sido tajante en señalar que "el asunto más frecuentemente discutido en historia antropométrica es la tendencia de la estatura media de una población en particular", así como realizar comparaciones entre países, justamente el foco de nuestro análisis.

Respecto del primer punto, y una vez establecida la buena calidad de nuestros datos, las principales conclusiones que emergen del análisis de los mismos son las siguientes:

I) A mediados del siglo XVIII, la estatura promedio de los soldados chilenos era relativamente alta, tanto en comparación con otros países del mundo como en relación a Chile mismo para la mayor parte del período considerado en este artículo, lo que se explicaría principalmente por la buena calidad de la dieta y la baja densidad poblacional;

II) La segunda mitad del siglo XVIII es un período relativamente negativo para el bienestar biológico de los soldados, concordante con aumentos de precios de los principales productos de la canasta básica de alimentos, pero se observa un claro repunte en las décadas de 1830-1840;

III) La segunda mitad del siglo XIX es un período de estancamiento en el bienestar nutricional, y a ratos de declive, a pesar del boom exportador, tal como ocurrió en otros países latinoamericanos en épocas de auge económico (López-Alonso, 2015). Esto se habría debido a un aumento en la desigualdad del ingreso, a las precarias condiciones de vida de la población, a la ingesta de una dieta pobre en carne y lácteos, a malos hábitos de higiene, al bajo nivel de educación y mala cobertura de salud, a un aumento de la urbanización en condiciones insalubres. Estas malas condiciones de vida contribuyeron a la propagación de numerosas epidemias (viruela, tifus, tuberculosis, cólera e influenza), así como a un inestable sistema de salud basado en la caridad privada, provocando altos niveles de mortalidad infantil y baja esperanza de vida;

IV) Como en muchos otros países (Steckel, 1995), se observan variaciones cíclicas en la estatura de los soldados en los siglos XVIII y XIX, en lugar de una tendencia secular;

V) El siglo XX es un período muy positivo, con un crecimiento sostenido en la estatura desde 1910 hasta los años setenta. Esto se habría debido a leves mejorías en la distribución del ingreso y en los salarios reales, a la propagación del higienismo en una población mejor educada (incluyendo mejores hábitos alimentarios), a un mejor sistema de salud (público, y con mayor cobertura), a los notables adelantos en la medicina y políticas de salud (que incluían masificación de antibióticos e introducción de vacunación obligatoria), a mejorías en la dieta (p.e., mayor consumo de leche materna y animal). Se introdujeron además notorios progresos en los sistemas de provisión de agua potable y alcantarillado. Estos avances se tradujeron en una importante reducción de la mortalidad infantil y en un aumento espectacular en la esperanza de vida.

Respecto de comparaciones con otros países de la región, la estatura de los soldados chilenos es superior a la de casi todos los países para los que hay evidencia comparable en América Latina, salvo para Argentina (Figura 6). No obstante lo anterior, al final del período, en el siglo XX, a pesar del crecimiento sostenido de la estatura promedio de Chile, la brecha con Brasil y Colombia se reduce significativamente, cosa que ocurre también con España, que incluso 
logra superar a Chile con creces. Comparado con países desarrollados, hasta el tercer cuarto del siglo XIX la estatura promedio de los soldados chilenos no era muy distinta de la de los suecos u holandeses. Sin embargo, desde inicios del siglo XX se observa un claro proceso de divergencia entre la estatu- ra promedio de Chile y la de estos países, así como de los Estados Unidos y el Reino Unido, lo que es coincidente con otros indicadores como el PIB per cápita: ocurre una historia muy similar. Esto es, se observa divergencia no solo en bienestar biológico, sino también en ingresos promedios (Figura 7).

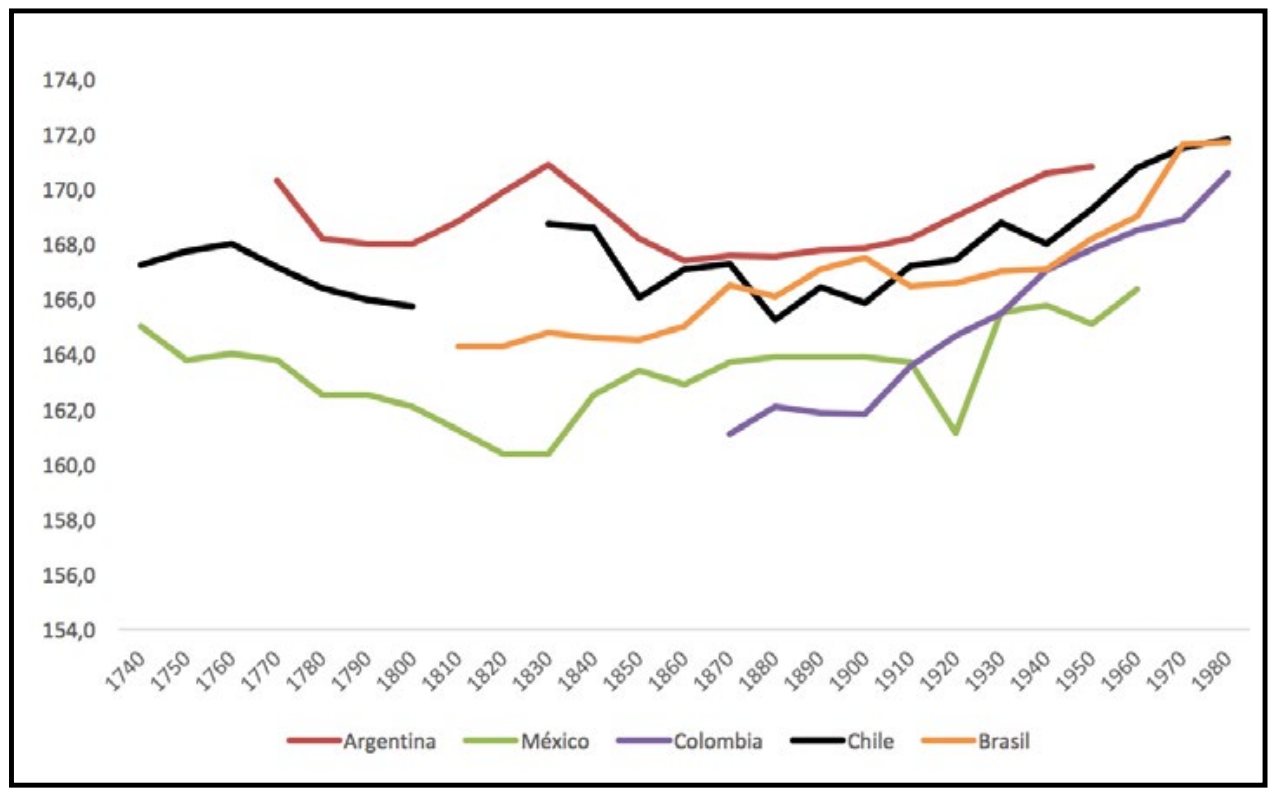

Figura 6. Estatura promedio de Chile y otros países latinoamericanos $(\mathrm{cm})$. Fuente: ANCH-CM y AHE.

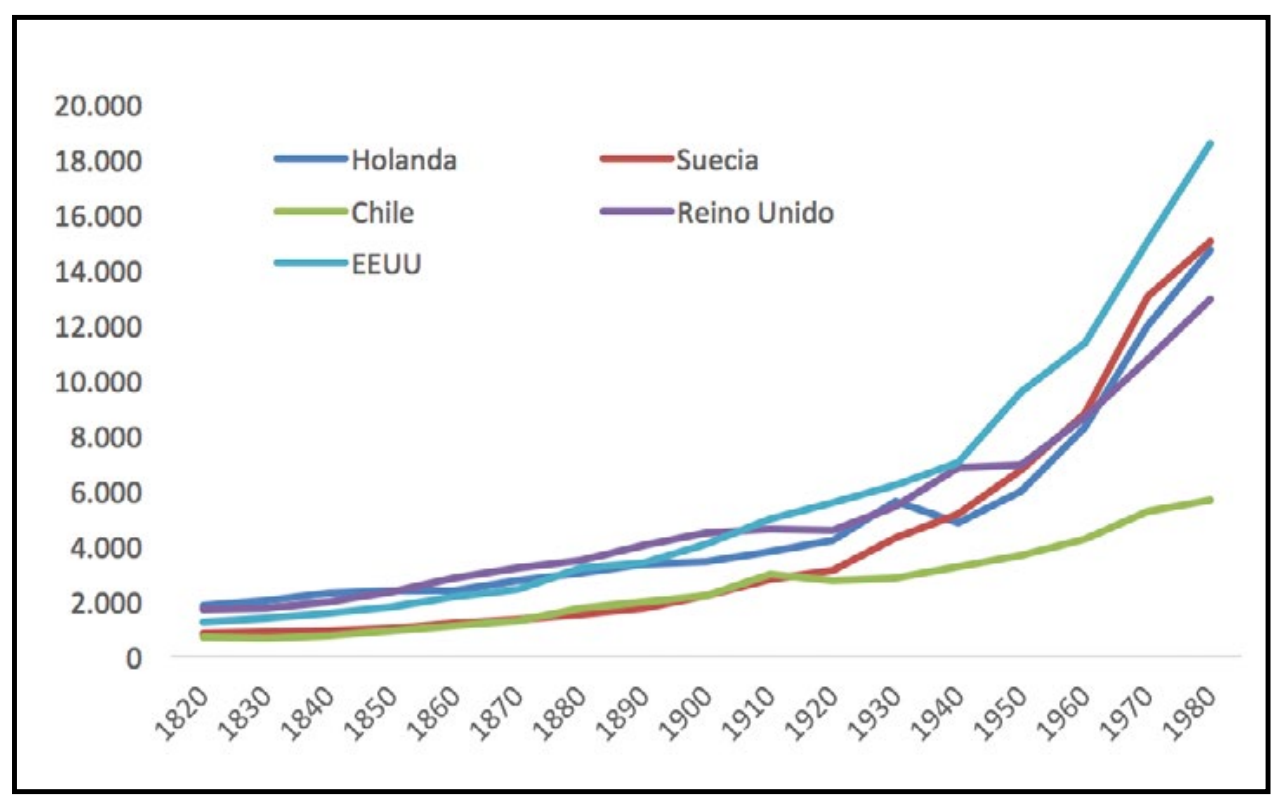

Figura 7. PIB per cápita real de Chile y países desarrollados, 1820-1980 (dólares internacionales Geary-Khamis de 1990). Fuente: Maddison, 2007. 
Finalmente, si comparamos nuestra serie de estatura promedio de la población chilena con la evolución del PIB per cápita chileno (Figura 8), ejercicio que podemos realizar solo desde 1830 en adelante, podemos constatar que la "historia" que nos cuenta la trayectoria del PIB per cápita real chileno es de un resonante éxito: el PIB per cápita real de nuestro país se habría más que octuplicado entre 1830 y 1980. En contraste, la evolución de la estatura promedio da cuenta de otra realidad bien distinta, que coincide con la trayectoria del PIB per cápita real solo en las últimas décadas del siglo XX. Tal como encon- traron otros colegas para México y Perú, a pesar del rápido crecimiento económico experimentado por Chile durante el siglo XIX, hubo solo un modesto aumento en el bienestar nutricional de la mayor parte de la población.

Respecto de agendas futuras de investigación, se hacen necesarios estudios adicionales para explicar con mayor profundidad las variaciones en el tiempo de la estatura promedio de la población, así como de los determinantes de la misma, en particular sobre cómo evolucionó la dieta de los chilenos en el largo

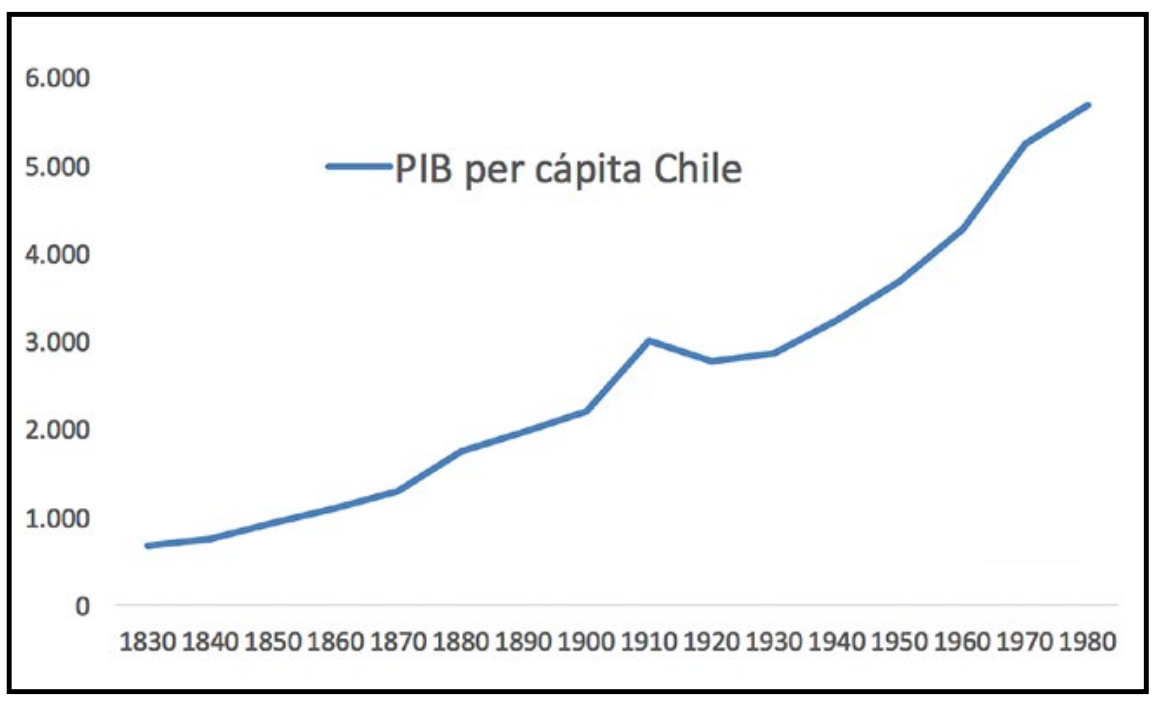

174

172

170

Estatura Chile

168

166

164

162

160

Figura 8. PIB per cápita real (US\$1990) versus estatura (cm), Chile (1830-1980).

Fuente: Para PIB per cápita, Maddison, 2007; para estatura, figuras anteriores. 
plazo (Yáñez, 2016 y 2017 ya constató dicha necesidad). Por último, haciendo uso de otras fuentes, deberíamos hacer esfuerzos adicionales para contrastar las estaturas masculinas que hemos encontrado con cifras similares para mujeres, así como con estaturas de otros grupos sociales, para de este modo poder aportar antecedentes adicionales a los estudios de desigualdad histórica en Chile.

\section{Agradecimientos}

Estamos muy agradecidos de la ayuda brindada por el personal del Departamento Cultural, Histórico y de Extensión del Ejército de Chile (DCHEE); especialmente el capitán Rodrigo Arredondo, el comandante Pedro Hormazábal, las investigadoras Claudia Arancibia y Camila Pesce, los suboficiales Raúl Carrasco, Enrique Lorca y Christian Capstick, y el personal civil Manuel Madrid y Dora Basoalto. Agradecemos también a Federico Droller, Claudio Robles, Rodrigo Araya y Ara Murillo.

\section{Referencias citadas}

Acosta, K., Meisel, A. (2013). Antropometric measurements by ethnicity in Colombia, 1965-1990. Economics \& Human Biology, 11(4), 416-425.

Aguilera, M. y Zúñiga, C. (2006). Politicas estatales de asistencia social en Chile: el problema de la leche, 1930-1970. Tesis para optar al grado de Licenciatura en Historia, Universidad de Chile.

Allen, R. C. (2001). The great divergence in European wages and prices from the middle ages to the First World War. Explorations in Economic History, 38, 411-447.

Allen, R. C., Bassino, J., Ma, D., Moll-Murata, C., Van Zanden, J. L. (2011). Wages, prices, and living standards in China, 1738-1925: in comparison with Europe, Japan, and India. Economic History Review, 64, 8-38.

Allen, R. C., Weisdorf, J. L. (2011). Was there an 'industrious revolution' before the industrial revolution? An empirical exercise for England, c.1300-1830. Economic History Review, 64, 715-729.

Allen, R. C., Murphy, T. E., Schneider, E. B. (2012). The colonial origins of the divergence in the Americas: a labor market approach. Journal of Economic History, 72, 863894.

Allende, J. (1963). Ejército y milicias del reino de Chile (1735-1815). Boletín de la Academia Chilena de la Historia, 66-68.

Allende, S. (1939). La realidad médico-social chilena. Santiago: Ministerio de Salubridad.

Baltzer, M., Baten, J. (2008). Height, trade $\&$ inequality in the Latin American periphery, 1950-2000. Economics \& Human Biology, 6-2, 191-203.

Baten, J., Pelger, I., Twrdek, L., (2009). Anthropometric history of Argentina, Brazil and Peru during the 19th and early 20th century. Economics and Human Biology, 7(3), 319-333.

Baten, J., Carson, S. (2010). Latin American anthropometrics, past and present -an overview. Economics and $\mathrm{Hu}$ man Biology, 8(1), 141-144.

Blum, M. (2016). Inequality and heights. En Komlos, J., Kelly, I. R. (Eds.). The Oxford Handbook of Economics and Human Biology. Oxford: Oxford University Press.

Bogin, B., Keep, R. (1998). Eight thousand years of human growth in Latin America: economic and political history revealed by anthropometry. En Komlos, J. y Baten, J. (Eds.). The biological standard of living in comparative perspective. Stuttgart: Franz Steiner Verlag.

Cabrera, M. J. (2008). ¿Obligar a vivir o resignarse a morir? En Zárate, M. S. (Comp.). Por la salud del cuerpo: historia y politicas sanitarias en Chile. Santiago: Universidad Alberto Hurtado.

Cámara Hueso, A. D. (2006). Fuentes antropométricas en España: Problemas metodológicos para los siglos XVIII y XIX. Historia Agraria, 38(1), 575-582.

Cárcamo, E., Almagia Flores, A. A. (2000). Estudio comparativo de mujeres y hombres: variables antropométricas de una población. Boletín Científico Asociación Chilena de Seguridad, 2(3), 59-66.

Carson, S. A. (2005). The biological standard of living in 19th Century Mexico and in the American West. Economics and Human Biology, 3(3), 405-419. 
Challú, A. (2009). Agricultural crisis and biological wellbeing in Mexico, 1730-1835. Historia Agraria, 47(1), 21-44.

Challú, A. (2010). Living standards and the great decline: biological well-being in Mexico, 1730-1840. En Salvatore, R. D., Coatsworth, J. H., Challú, A. E. (Eds.). Living standards in Latin American History: heights, welfare and development, 1750-2000. Cambridge-MA: Harvard University Press.

Costa, M. A. J., Neves, W. A., Hubbe, M. (2004). Influencia de Tiwanaku en la calidad de vida biológica de la población prehistórica de San Pedro de Atacama. Estudios Atacameños, 27, 103-106.

Cruz-Coke, E. (1928). Los equilibrios alimenticios y la alimentación del pueblo chileno. Revista Médica de Chile, 4(1), 319-348.

Cruz-Coke, R. (1995). Historia de la medicina chilena. Santiago: Andrés Bello.

Cussen, C. (2016). Relato histórico de la formación del actual pueblo chileno. En Berríso, S. (Ed.). El ADN de los chilenos y sus orígenes genéticos. Santiago: Universitaria.

Deichler, C. (2016). Historia y Alimentación Popular. Dos décadas de lucha médica contra la desnutrición en el Chile urbano, 1930-1950. Santiago: Ministerio de Salud.

Delgado, F. (2015). Deserción, disciplinamiento y alistamiento militar. A propósito de la instauración del Servicio Militar Obligatorio en Chile, 1885-1901. Historia (Universidad de Concepción), 22(2), 63-79.

Díaz, J., Lüders, R. y Wagner, G. (2016). Chile 1810-2010. La República en Cifras. Santiago: Ediciones UC.

Dobado, R. (2015). Pre-independence Spanish Americans: poor, short and unequal... or the opposite? Revista de Historia Económica-Journal of Iberian and Latin American History, 33(1), 15-59.

Dobado, R., García-Montero, H. (2014). Neither so low nor so short: wages and heights in Bourbon Spanish America from an international comparative perspective. Journal of Latin American Studies, 46(2), 291-321.

Eltis, D. (1982). Nutritional trends in Africa and the Americas: heights of Africans, 1819-1839. Journal of Interdisciplinary History, 12(3), 453-475.
Erazo, M., Amigo, H., Bustos, P. (2005). Etnia mapuche $\mathrm{y}$ condiciones socioeconómicas en la estatura del adulto. Revista Médica de Chile, 133(4), 461-468.

Fernández, E. (2015). Estudio sobre la génesis y la realización de una estructura urbana: la construcción de la red de alcantarillado de Santiago de Chile (1887-1910). Historia, 48(1), 119-193.

Floud, R., Gregory, A., Wachter, K. W. (1990). Height, health and history: nutritional status in the United Kingdom, 17501980. Cambridge: Cambridge University Press.

Fogel, R. W. (1993). New sources and new techniques for the study of secular trends in nutritional status, health, mortality, and the process of aging. Historical Methods, 26(1), 5-38

Fogel, R. W. (2004). The escape from hunger and premature death, 1700-2100. Cambridge: Cambridge University Press.

Fogel, R. W., Engerman, S. L., Floud, R., Friedman, G., Margo, R. A., Sokoloff, K., Steckel, R. H., Trussell, T. J., Villaflor, G., Wachter, K. (1983). Secular Changes in American and British Stature and Nutrition. Journal of Interdisciplinary History, 14(2), 445-81.

Frank, Z. (2006). Stature in nineteenth-century Rio de Janeiro: preliminary evidence from prison records. Revista de Historia Económica-Journal of Iberian and Latin American History, 24(3), 465-490.

Godoy, R. A. (2006). Physical stature of adult Tsimane' Amerindians, Bolivian Amazon in the 20th century. Economics and Human Biology, 4(2), 184-205.

González, R. (1935). Cómo se alimenta la familia obrera en Santiago. Revista de Medicina y Alimentación, 2(1), 15-25.

Grajales-Porras, A., López-Alonso, M. (2011). Physical stature of men in eighteenth century Mexico: evidence from Puebla. Economics \& Human Biology, 9(3), 265-271.

Illanes, M. A. (1993). En el nombre del pueblo, del estado y de la ciencia: historia social de la salud pública, Chile 1880 1973. Santiago: Colectivo de Atención Primaria.

Kelly, I. R.; Komlos, J. (2016). Introduction. En Komlos, J., Kelly, I. R. (Eds.). The Oxford Handbook of Economics and Human Biology. Oxford: Oxford University Press. 
Komlos, J. (1985). Stature and Nutrition in the Habsburg Monarchy: The Standard of Living and Economic Development. American Historical Review, 90, 1149-1161.

Komlos, J. (1989). Nutrition and economic development in the eighteenth century Habsburg Monarchy. New Jersey: Princeton University Press.

Komlos, J. (Ed.). (1994). Stature, living standards and economic development: essays in anthropometric history. Chicago: Chicago University Press.

Komlos, J. (1998). Shrinking in a growing economy? The mystery of physical stature during the industrial revolution. Journal of Economic History, 58(3), 779-802.

Komlos, J. (2002). How to Analyze Historical Heights using Truncated Samples. Unpublished Working Paper, University of Munich.

Komlos, J. (2004). How to (and how not to) analyze deficient height samples: an introduction. Historical Methods, $37,160-173$.

Komlos, J., Kim, J. H. (1990). Estimating trends in historical heights. Historical Methods, 23, 116-120.

Komlos, J., Baten, J. (Eds.). (1998). The biological standard of living in comparative perspective. Stuttgart: Franz Steiner Verlag.

Ladurie, L. R., Bernageau, E. N., Pasquet, Y. (1969). Le Conscrit et l'ordinateur: Perspectives de recherches sur les archives militaires du XIXe siècle français. Studi Storici, 10, 260-308.

León, L. (2002a). Bajo pueblo y Cabildo en Santiago de Chile colonial, 1758-1768. Contribuciones Científicas y Tecnológicas, 130, 61-94.

León, L. (2002b). Reclutas forzados y desertores de la Patria: el bajo pueblo chileno durante la guerra de la Independencia, 1810-1830. Historia, 35, 251-297.

Lettre, G. (2009). Genetic regulation of adult stature. Current Opinion in Pediatrics, 21(4), 515-522.

Llorca-Jaña, M., Navarrete-Montalvo, J. (2015). The real wages and living conditions of construction workers in Santiago de Chile during the later colonial period, 17881808. Investigaciones de Historia Económica-Economic History Research, 11(2), 80-90.
López, M. (2015). Medicina, politica y bien común: 40 años de historia del programa de control de la tuberculosis (19732013). Santiago: Ministerio de Salud.

López-Alonso, M. (2007). Growth with Inequality: Living Standards in Mexico, 1850-1950. Journal of Latin American Studies, 39(1), 81-105.

López-Alonso, M. (2015). Estar a la altura. Una historia de los niveles de vida en México, 1850-1950. México: Fondo de Cultura Económica.

López-Alonso, M. (2016). Economics and human biology in Latin America. En Komlos, J., Kelly, I. R. (Eds.). The Oxford Handbook of Economics and Human Biology. Oxford: Oxford University Press.

López-Alonso, M., Porras-Condey, R., (2003). The ups and downs of Mexican economic growth: the biological standard of living and inequality, 1870-1950. Economics and Human Biology, 1(2), 169-186.

López-Alonso, M., Grajales-Porras, A. (2015). Measuring inequality in living standards with anthropometrics indicators: the case of Mexico, 1850-1986. Journal of Human Development \& Capabilities, 16(3), 374-396.

Mac-Clure, Oscar (2012). En los origenes de las politicas sociales en Chile, 1850-1879. Santiago: Ediciones Universidad Alberto Hurtado.

Maddison, A. (2007). Historical Statistics of the World Economy: 1-2008 AD. Oxford: Oxford University Press.

Mardones, J. (1935). El problema de la alimentación en Chile. Revista de Medicina y Alimentación, 6(1), 367-378.

Margo, R. A., Steckel, R. (1982). The heights of American slaves: new evidence on slave nutrition and health. Social Science History, 6(4), 511-538.

Márquez, L. y Del Angel, A. (1997). Height among prehispanic Maya of the Yucatán Peninsula: reconsideration. En Whittington, S. M. and Reed, D. L. (Eds.). Bones of the Maya: studies of ancient skeletons. Washington: Smithsonian Institution.

Márquez, L., Mccaa, R., Storey, R., Del Angel, A. (2002). Health and nutrition in pre-Hispanic Mesoamerica. En Steckel, R. H. y Rose, J. C. (Eds.). The Backbone of his- 
tory: Health and Nutrition in the Western Hemisphere. Cambridge: Cambridge University Press.

Martínez, J. J. (2016). Consumo y comercio de carnes en el corregimiento de Santiago, 1773-1778. Ponencia presentada en el Quinto Congreso Latinoamericano de Historia Económica, Sao Paulo.

McCaa, R., Márquez, L., Storey, R. y Del Angel, A. (2002). Health and nutrition in prehispanic Mesoamerica. En Steckel, R. H. y Rose, J. C. (Eds.). The Backbone of history: Health and Nutrition in the Western Hemisphere. Cambridge: Cambridge University Press

Meisel, A., Vega, M. (2007). The biological standards of living (and its convergence) in Colombia, 1870-2003 a tropical success story. Economics and Human Biology, 5(1), 100-122.

Mokyr, J. y Stein, R. (1996). Science, Health, and Household Technology: The Effect of the Pasteur Revolution on Consumer Demand. In Bresnahan, T. F., y Gordon, R. J. (Eds.). The Economics of New Goods (pp. 143-206). Chicago: University of Chicago Press.

Monasterio, L. M. (2013). Estatura e inmigración en el sur de Brasil, 1889-1914. América Latina en la Historia Económica, 21(11), 115-133.

Musalem, J. (1950). Los problemas de la alimentación y los acuerdos de Hot Springs. Memorias de Licenciados en Ciencias Económicas. Santiago: Jurídica de Chile.

Núñez, J., Pérez, G. (2015). Trends in physical stature across socioeconomic groups of Chilean boys, 1880-1997. Economics and Human Biology, 16(1), 100-114.

Oliveira, V. H. de, Quintana-Domeque, C. (2014). Earlylife environment and adult stature in Brazil: an analysis for cohorts born between 1950 and 1980. Economics and Human Biology, 15(1), 67-80.

Ossa, J. L. (2016). La reconstrucción del ejército de Chile en una era reformista (1762-1810). Economía y Politica, 3(1), 103-131.

Pinto, J., Salazar, G. (1999). Historia Contemporánea de Chile. Actores, Identidad y Movimiento, vol. II. Santiago: LOM Ediciones.
Ramón, A. de (1992). Santiago de Chile (1541-1991): historia de una sociedad urbana. Madrid: Editorial Mapfre.

Retamal, J. (1993). Características físicas del chileno del siglo XVII. Historia, 27, 449-504.

Rodríguez, J. (2017). Desarrollo y desigualdad en Chile, 1850-2009. Historia de su economía politica. Santiago: Dibam.

Rojas, J. (2010). Los rasgos físicos de los chilenos. En Góngora, A., Sagredo, R. (Eds.). Fragmentos para una historia del cuerpo en Chile. Santiago: Taurus.

Salvatore, R. D. (1998). Heights and welfare in late-colonial and post-independence Argentina. En Komlos, J. y Baten, J. (Eds.). The biological standard of living in comparative perspective. Stuttgart: Franz Steiner Verlag.

Salvatore, R. (2004). Stature decline and recovery in a food-rich export economy: Argentina 1900-1934. Explorations in Economic History, 41, 233-255.

Salvatore, R. (2007). Height, nutrition and well being in Argentina, ca. 1850-1950, preliminary results. Journal of Iberian and Latin American Economic History, 25(1), 53-86.

Salvatore, R. (2009). Stature growth in industrializing Argentina: the Buenos Aires industrial belt 1916-1950. Explorations in Economic History, 46(1), 70-92.

Salvatore, R. D., Coatsworth, J. H., Challú, A. E. (Eds.). (2010). Living standards in Latin American History: heights, welfare and development, 1750-2000. Cambridge-MA: Harvard University Press.

Salvatore, R. D., Baten, J. (1998). A most difficult case of estimation: Argentinian heights, 1770-1840. Komlos, J. y Baten, J. (Eds.). The biological standard of living in comparative perspective. Stuttgart: Franz Steiner Verlag.

Santa María, J. (1935). La alimentación de nuestro pueblo. Santiago: Talleres de San Vicente.

Santa María, J. (1941). Características de la alimentación en Chile. Revista Médica de Chile, 6(1), 308-322.

Scriggie, A. (1942). El problema de la leche. Revista Chilena de Pediatría, 10(1), 863-368. 
Sierra, L., Moore, E. (1895). La mortalidad de los niños en Chile. Valparaíso: Imprenta y Litografía Central.

Steckel, R. H. (1995). Stature and the standard of living. Journal of Economic Literature, 33(4), 1903-1940.

Steckel, R. H. (1997). Slave height profiles from Coastwise manifests. Explorations in Economic History, 16(4), 363380.

Steckel, R. H. (2005). Health and nutrition in pre-Columbian America: the skeletal evidence. Journal of Interdisciplinary History, 36(1), 1-32.

Steckel, R. H. (2009). Heights and human welfare: recent developments and new directions. Explorations in Economic History, 46(1), 1-23.

Twrdek, L., Manzel, K. (2010). The seed of abundance and misery Peruvian living standards from the early republican period to the end of the guano era (1820-1880). Economics and Human Biology, 8, 145-152.

Urriola, R. (2009). Historia de la protección social de la salud en Chile, 1810-2010. En Urbina, Leandro (Ed.). Historia de la protección social de la salud en Chile. Santiago: LOM Ediciones.

Vercellotti, G., Piperata, B. A., Agnew, A. M., Wilson, W. M., Dufour, D. L., Reina, J. C., Boano, R., Justus, H.
M., Larsen, C. S., Stout, S. D., Sciulli, P. W. (2014). Exploring the multidimensionality of stature variation in the past through comparisons of archaeological and living populations. American Journal of Physical Anthropo$\log y, 155,229-242$.

Villalobos, S. (1961). Tradición y reforma en 1810. Santiago: Universidad de Chile.

Wachter, K. W. (1981). Graphical estimation of military heights. Historical Methods, 14(1), 31-42.

Yáñez, J. C. (2016). “Alimentación abundante, sana y barata”. Los restaurantes populares en Santiago (1936-1942). Cuadernos de Historia, 45(2), 117-142.

Yáñez, J. C. (2017). El problema de la alimentación: un enfoque desde las encuestas de nutrición. Chile, 1928-1938. América Latina en la Historia Económica, 24(1), 66-97.

Zárate, M. S. (2008). Por la salud del cuerpo. En Zárate, M. S. (Comp.). Por la salud del cuerpo: historia y politicas sanitarias en Chile. Santiago: Universidad Alberto Hurtado.

Zárate, M. S. (2013). El licor de la vida. Lactancia y alimentación materno-infantil, Chile (1900-1950). En Sciolla, C. (Comp.). Historia y cultura de la alimentación en Chile: miradas y saberes sobre nuestra culinaria. Santiago: Catalonia. 